\title{
A comprehensive review on flavanones, the major citrus polyphenols
}

\author{
Muhammad Kamran Khan ${ }^{\text {a,*, }}$ Zill-E-Huma ${ }^{\text {b }}$, Olivier Dangles ${ }^{c}$ \\ ${ }^{a}$ Department of Food Science, Government College University, Faisalabad, Pakistan \\ ${ }^{\mathrm{b}}$ National Institute of Food Science E Technology, University of Agriculture, Faisalabad, Pakistan

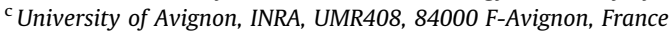

Keywords:

Citrus fruit

Orange

Grapefruit

Polyphenol

Flavanone

Chalcone

Conjugate

Glucuronide

Metabolites

Synthesis

Extraction

Analysis

Bioavailability

Bioactivity

Food composition

\begin{abstract}
A B S T R A C T
The consumption of Citrus fruits and juices has been widely investigated for its possible role in the prevention of cardiovascular disease and cancer. These beneficial effects are mainly attributed to flavanones, the typical polyphenols of Citrus species. Major flavanones in plant species include hesperetin, naringenin, eriodictyol, isosakuranetin and their respective glycosides. Hesperetin and its derivatives are characteristic flavanones of sweet orange, tangelo, lemon and lime, while naringenin and its derivatives are those of grapefruit and sour orange. Advances in analytical techniques like ultra high performance liquid chromatography (UPLC) coupled with mass spectrometry has facilitated (a) the estimation of flavanone contents in other plant species and in humans after ingestion and (b) the determination of flavanone metabolites more rapidly and with greater efficiency. The present review will summarize the current knowledge about flavanones from their occurrence in plants to the bioactivity of their metabolites in humans.
\end{abstract}

\section{Contents}

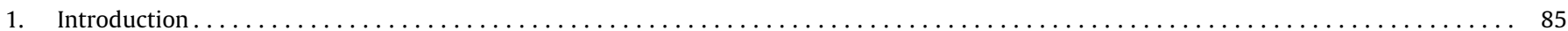

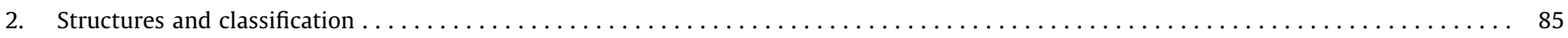

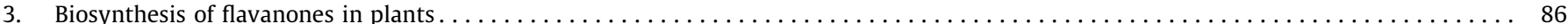

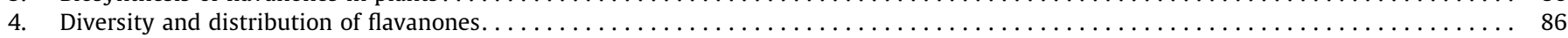

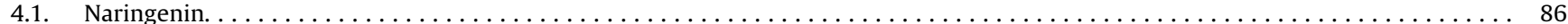

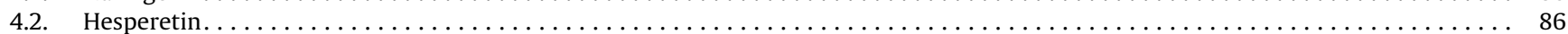

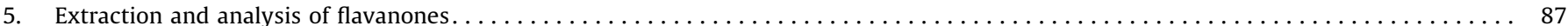

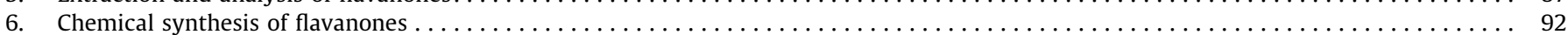

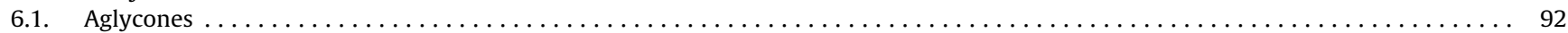

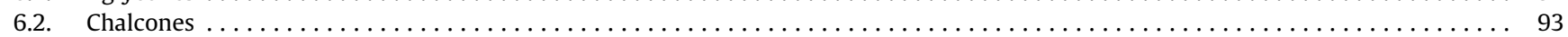

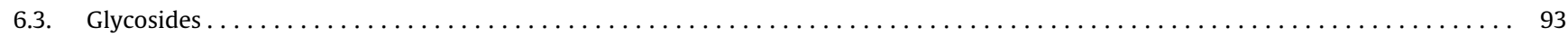

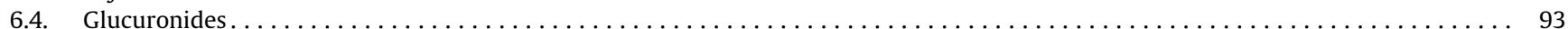

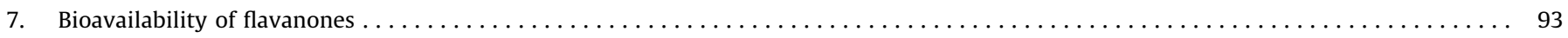

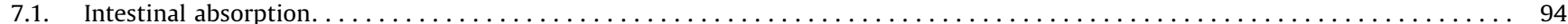

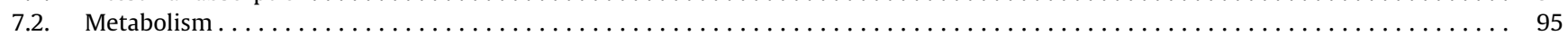

8. Interaction of flavanones with human serum albumin $\ldots \ldots \ldots \ldots \ldots \ldots \ldots$

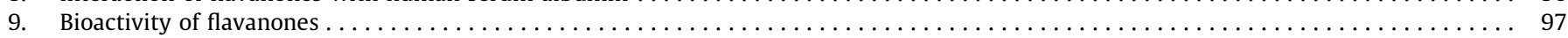

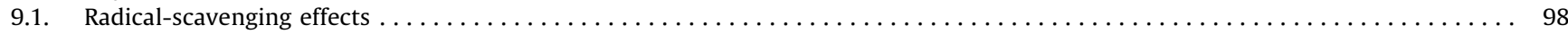

* Corresponding author. Tel.: +92 3474495 648; fax: +92 419200671.

E-mail address: mk.khan@gcuf.edu.pk (M.K. Khan). 
Version définitive du manuscrit publiée dans / Final version of the manuscript published in :

\section{Journal of Food Composition and Analysis (2014),vol 33, p 85-104, DOI: 10.1016/j.jfca.2013.11.004}

Journal homepage: www.elsevier.com/locate/jfca

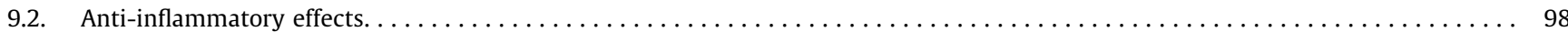

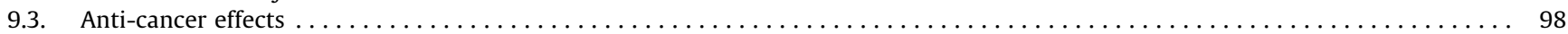

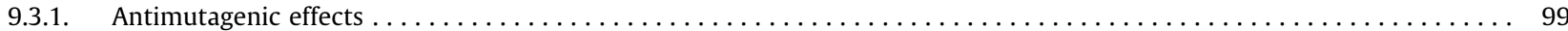

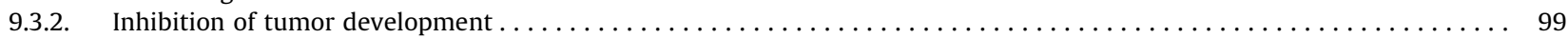

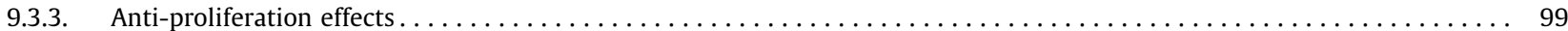

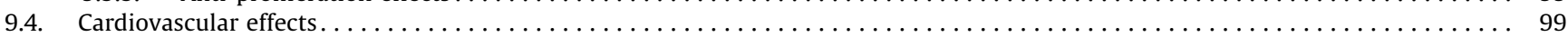

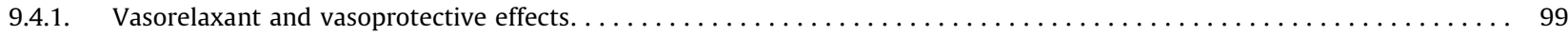

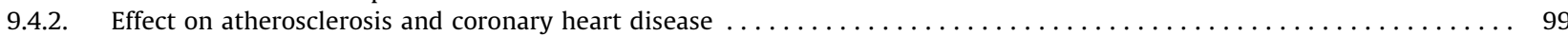

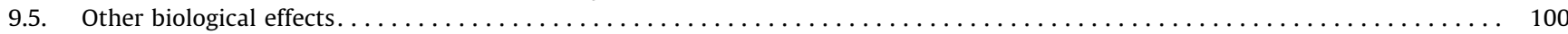

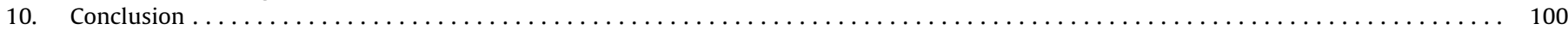

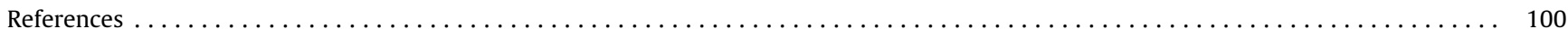

\section{Introduction}

It is now well accepted that a low consumption of fatty foods, a regular physical activity and a high consumption of plant-derived foods help to maintain a good health status. In particular, there is an association between an increased level of fruit and vegetables in the diet and a reduced risk of some life-threatening diseases such as cardiovascular disease and cancer (Parr and Bolwell, 2000). There is also growing acceptance that many phenolic secondary metabolites (polyphenols) present in plant-derived foods exert beneficial effects in the prevention of these degenerative diseases (Benavente-Garcia and Castillo, 2008; Del Rio et al., 2010). Moreover, Citrus fruit and juices are highly consumed worldwide and this consumption has significantly increased during the past few years. Global production of Citrus fruit reached 82 million tons in the years 2009-2010, of which oranges - commercially the most important citrus fruit accounts for about 50 million tons (USDA, 2010). Worldwide Citrus consumption has thus stimulated research on the most abundant Citrus phenols, i.e. flavanones. Based on the criterion of flavanone content, Citrus plants belonging to the Rutaceae family appear especially important. This review will cover the updated literature available on the chemistry and biochemistry of the main Citrus flavanones, hesperetin and naringenin.

\section{Structures and classification}

A few decades ago, flavanones were considered as only minor flavonoids (Bohm, 1994), like chalcones, dihydrochalcones, dihydroflavonols and aurones. However, during the past 15 years, the total number of known flavanones has increased to the point that they are now considered a major flavonoid class like flavones, isoflavones, flavanols, flavonols and anthocyanidins (Veitch and Grayer, 2006). Up to now about 350 flavanone aglycones and 100 flavanone glycosides have been identified in nature (Iwashina, 2000).

Generally, polyphenols are classified into two major classes: flavonoids and nonflavonoids. The latter include structurally simple molecules such as phenolic acids (hydroxybenzoic acids and hydroxycinnamic acids) and stilbenes, and highly complex molecules such as stilbene oligomers, tannins and lignins (Cheynier, 2005). The former, the most studied class of polyphenols, includes more than 9000 identified compounds (Martens and Mithöfer, 2005; Pietta, 2000). Flavonoids commonly share the same generic structure, the flavan nucleus, consisting of two aromatic rings ( $\mathrm{A}$ and $\mathrm{B}$ ) linked by a pyran ring (C). Differences in the location of the B-ring to C-ring linkage make it possible to distinguish between flavonoids (2-phenylbenzopyrans), isoflavonoids (3-phenylbenzopyrans), and neoflavonoids (4-phenylbenzopyrans). The by far the most abundant 2-phenylbenzopyran group may be further divided into 3-hydroxyflavonoids (flavonols, flavanols, anthocyanidins, dihydroflavonols), and flavonoids without substituent at C3 (flavanones and flavones). Flavones differ from flavanones by a C2-C3 double bond (Marais et al., 2006). The flavanone class encompasses a wide array of compounds with
$O$ - and/or C-substitutions at the A- or B-ring, e.g., hydroxy, methoxy, methylenedioxy, $O$ - and $C$-glycosyl, $C$-methyl, $C$-benzyl, C-hydroxymethyl, C-formyl, C-isoprenyl substituents (including furano or dihydrofurano rings), conjugations to stilbene, anastatin, phenolic acid, and diarylheptanoid moieties (Fig. 1) (Veitch and Grayer, 2006, 2008).

\section{Biosynthesis of flavanones in plants}

Due to the diverse physiological functions in plants and beneficial effects on human health, flavonoids are now attractive targets for genetic engineering strategies. In most plant species, the flavonoid biosynthetic pathway has been almost completely elucidated. In general, the biosynthesis of flavonoids is initiated by the two precursors, malonyl-CoA and $p$-coumaroyl-CoA, which are originated from carbohydrate metabolism and the phenylpropanoid pathway, respectively. After condensation of three molecules of malonyl-CoA with one molecule of $p$-coumaroyl-CoA, the yellow $2^{\prime}, 4,4^{\prime}, 6^{\prime}$-tetrahydroxychalcone is formed. This step is catalyzed by chalcone synthase (CHS). The unstable chalcone is then cyclized to the corresponding 4',5,7-trihydroxyflavanone by the enzyme chalcone isomerase $(\mathrm{CHI})$. Flavanones may be regarded as the cornerstone of flavonoid biosynthesis as they are the precursors of all other flavonoid classes (Fig. 2) (Martens and Mithöfer, 2005; Schijlen et al., 2004). Moreover, in Citrus species, UDP-glucose flavanone-7-O-glucosyltransferase (UFGT) and UDP-rhamnose flavanone glucoside rhamnosyltransferase (UFGRT) sequentially convert the flavanone aglycones into their $7-O-\beta$-D-glucosides and rhamnoglucosides (Lewinsohn et al., 1989) (Fig. 3).

Naturally occurring flavanones display the $(S)$ configuration at $\mathrm{C}_{2}$ (Tomas-Barberan and Clifford, 2000) as a consequence of the enantioselectivity of the chalcone isomerase ( $\mathrm{CHI}$ )-catalyzed intramolecular Michael addition within the chalcone precursor (Jez and Noel, 2002a). However, mixtures of (2R)- and (2S)hesperidin epimers in an approximate molar ratio of $1 / 6$ was detected in orange juice (Si-Ahmed et al., 2010), possibly because of the propensity of flavanone glycosides to undergo epimerization at $\mathrm{C} 2$ via the chalcone form. In the $\mathrm{CHI}$-catalyzed cyclization, the enone moiety of $2^{\prime}, 4,4^{\prime}, 6^{\prime}$-tetrahydroxychalcone is locked in an $s$ trans conformation. Electrophilic activation of the $\mathrm{C}=\mathrm{O}$ group involves a water molecule bound to the Tyr106 phenolic $\mathrm{OH}$ group and to the $\mathrm{OH}$ group of the Thr48 side chain. The main hydrogen bonds established between $\mathrm{CHI}$ and the flavanone product are represented on Fig. 4 (Jez et al., 2002b).

The concentrations of biosynthesis enzymes may play an important role in defining the distribution of flavanones in the different parts of the fruit. For instance, in the peel of Solanum lycopersicum (a tomato variety), the level of gene expression is lower for $\mathrm{CHI}$ than for CHS and flavanone 3-hydroxylase, which results in a high accumulation of naringenin chalcone (Iijima et al., 2008). This biosynthetic pathway is extensively investigated to outline the role of flavonoids in different physiological functions of plants such as insect-plant interactions (Simmonds, 2001), pigmentation (Mato et al., 2000), heavy metal tolerance (Keilig and Ludwig-Müller, 
Version définitive du manuscrit publiée dans / Final version of the manuscript published in :

Journal of Food Composition and Analysis (2014),vol 33, p 85-104, DOI: 10.1016/i.j.jca.2013.11.004

Journal homepage: www.elsevier.com/locate/jfca<smiles>O=C(OCc1ccccc1)O[C@H]1C(=O)c2ccccc2O[C@@H]1c1ccccc1</smiles>

$(2 S)$-Flavanone<smiles>C=C(C)[C@H](O)Cc1c(O)c(CC=C(C)C)c2c(c1O)C(=O)C[C@@H](c1ccc(O)c(O)c1)O2</smiles>

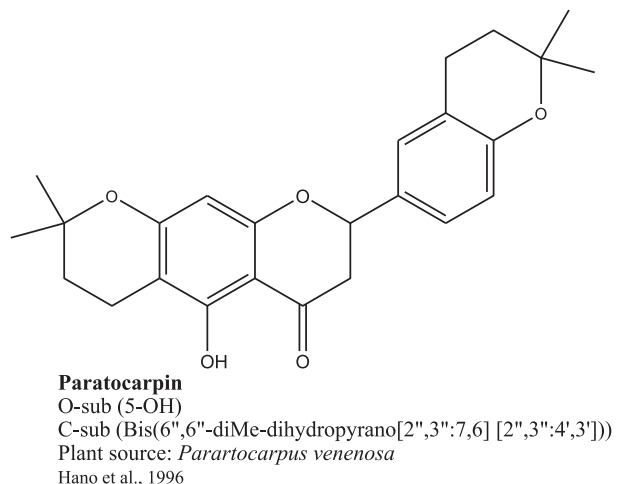

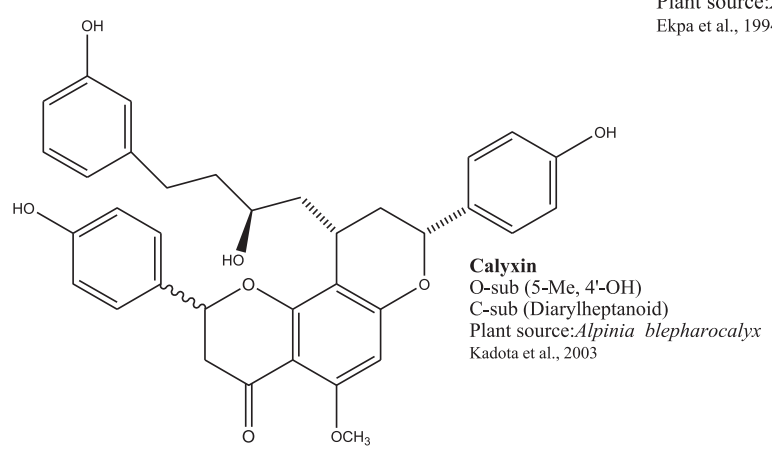<smiles>COc1c(C)c2c(c(O)c1C=O)C(=O)CC(c1ccccc1)O2</smiles><smiles>CC(C)=CCc1c(O)c2c(c3cc(C(C)(C)O)oc13)O[C@@H](c1ccc(O)cc1)CC2=O</smiles>
Plant source: Lupinus luteus<smiles>O=C1C[C@H](c2ccccc2)Oc2c(Cc3cc(Cc4ccccc4O)ccc3O)c(O)c(Cc3ccccc3O)c(O)c21</smiles>

Fig. 1. Chemical diversity of flavanones in nature

2009), disease resistance and UV-screening (Cooper-driver and Bhattacharya, 1998). Recently, Fowler and Koffas (2009) have reviewed the biotechnological production of flavanones by using various microorganisms. Alternatively, some works have tried to reduce the levels of flavanones because of their bitter taste. For example, an Agrobacterium-mediated approach targeting the CHS and $\mathrm{CHI}$ genes has been used to reduce the naringin contents in grapefruit (Koca et al., 2009).

\section{Diversity and distribution of flavanones}

Flavanones are widely distributed in about 42 higher plant families especially in Compositae, Leguminosae and Rutaceae (Iwashina, 2000). Depending on the plant type, flavanones can be found in all plant parts, above and below ground, from vegetative part to generative organs: stem, branches, bark, flowers, leaves, roots, rhizomes, seeds, fruits, peels etc.... The highest concentrations of flavanones are found in peel as compared to the fleshy part of Citrus fruit (Nogata et al., 2006). Among flavanones, the naringenin and hesperetin aglycones and their glycosides are of particular interest because of their high prevalence in foods.

\subsection{Naringenin}

Naringenin (5,7,4'-trihydroxyflavanone) is found in high concentrations in Citrus fruit while low concentrations are also found in tomatoes and their products (Erlund, 2004). Naringenin can be found as aglycone and/or as glycosides. Among the latter, naringin and narirutin are especially abundant. Naringin (naringenin-7neohesperidoside, Fig. 3 ) has a bitter taste due to its glucose moiety. 
Version définitive du manuscrit publiée dans / Final version of the manuscript published in :

Journal of Food Composition and Analysis (2014),vol 33, p 85-104, DOI: 10.1016/j jifca.2013.11.004

Journal homepage: www.elsevier.com/locate/jfca
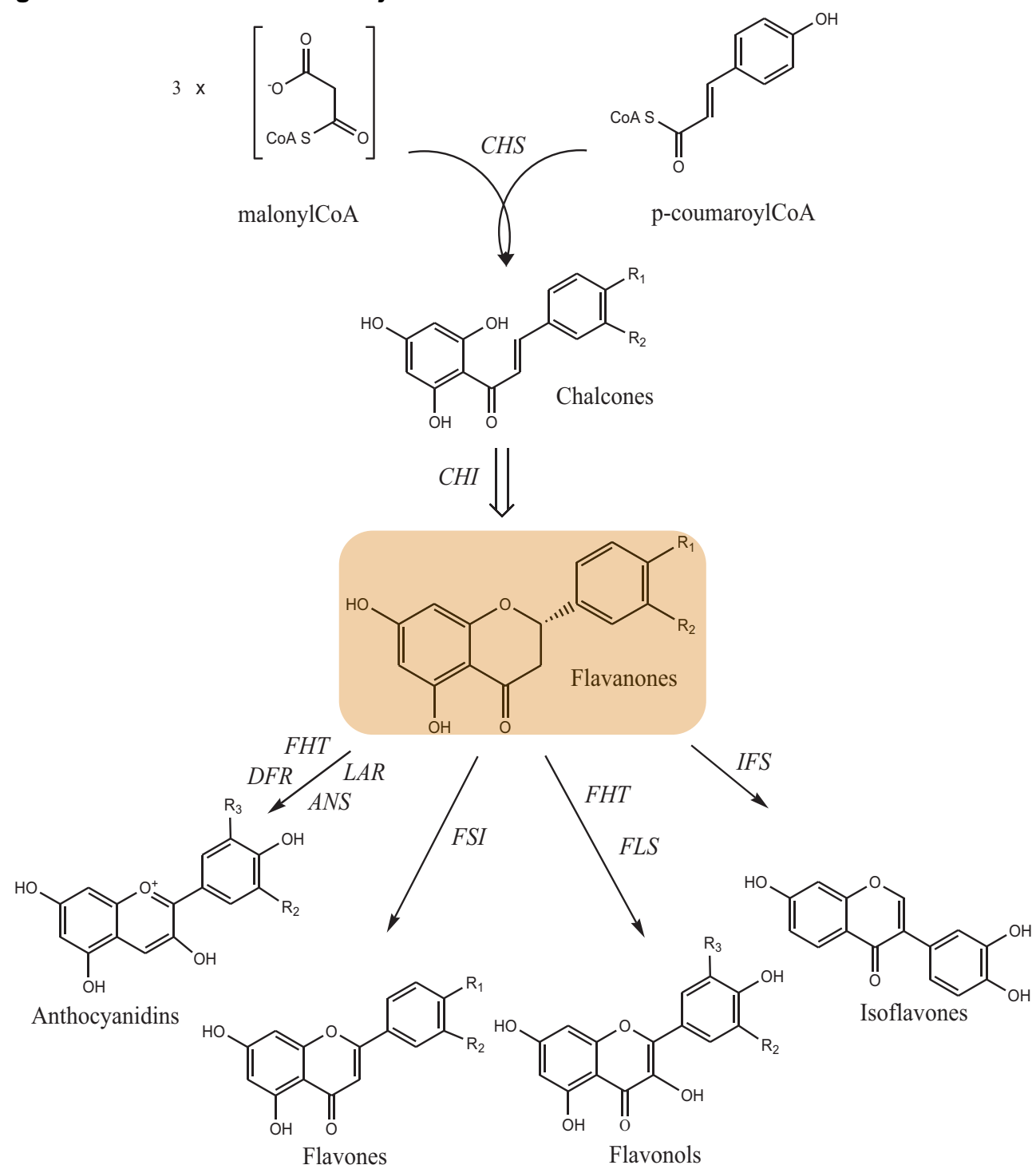

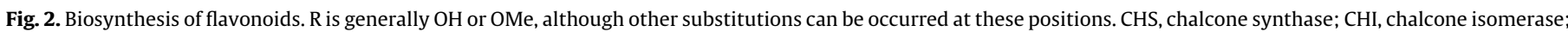

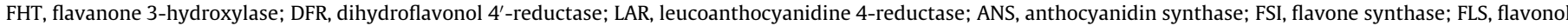
synthase; IFS, 2-hydroxyisoflavone synthase.

It is the major flavonoid in grapefruit and sour orange (Igual et al., 2013), which present different naringin contents depending on their varieties (Table 1). Other Citrus species like sweet orange, tangelo, lemon and lime exhibit low quantities of naringin. Another major naringenin glycoside, narirutin (naringenin-7-rutinoside, Fig. 3) is most abundant in grapefruit although less than naringin. Significant levels of narirutin are also detected in tangor, sweet orange, tangerine and tangelo (Peterson et al., 2006a). The processing of these fruits may significantly affect the naringenin content due to release of bound flavanones and/or degradation of these heatsensitive compounds. The effect can be clearly observed by comparing the naringenin contents of grapefruit and its jam (see Table 1) (Igual et al., 2013). The naringenin chalcone is found in higher quantities in tomato peel, which also contains some other flavanone chalcones (Slimestad et al., 2008).

\subsection{Hesperetin}

As naringenin, hesperetin (4'-methoxy-5,7,3'-trihydroxyflavanone) and its glycosides are also mainly present in Citrus fruit. The aglycone is less dominant in nature than the glycosides. The most widely distributed glycosides of hesperetin are hesperidin and neohesperidin, which are conjugates with rutinose and neohesperidose, respectively. Hesperidin (hesperetin-7-rutinoside, Fig. 3) is present in higher extents in lemons, limes, sweet oranges, tangerine and tangor species of citrus fruits (Cano et al., 2008), while neohesperidin (hesperetin-7-neohesperidoside, Fig. 3) is absent in them. Among all, sweet oranges are greatly studied for their phenolic contents and Table 1 presents the data for fruits from different regions (Cyprus, Mauritious). Although variations in the hesperetin content are detected, the ratio of the hesperetin to naringenin contents is approximately constant (Goulas and Manganaris, 2012; Ramful et al., 2011). Significant amounts of hesperetin also occur in grapefruits while tangelo and sour orange are especially rich in neohesperidin (Peterson et al., 2006a, 2006b).

\section{Extraction and analysis of flavanones}

Owing to the chemical complexity and the vast distribution of flavanones in plant, extraction and analysis of flavanones remain as challenging as ever, despite the recent advances in analytical instrumentation. After the detailed analysis of phenolic composition of citrus fruit and juice (edible parts), nowadays, more attention is focused on their by-products. In fact, the domestic and 
Version définitive du manuscrit publiée dans / Final version of the manuscript published in :

Journal of Food Composition and Analysis (2014),vol 33, p 85-104, DOI: 10.1016/i.j.jca.2013.11.004

Journal homepage: www.elsevier.com/locate/jfca

Sugars

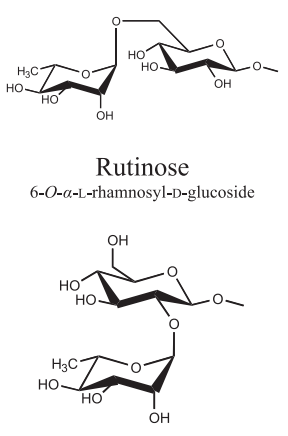

Neohesperidose Neohesperidose
2-O- $\alpha$-L-rhamnosyl-D-glucoside
Aglycones<smiles>[R]c1cc(O)c2c(c1)OC(c1ccc(O)cc1)CC2=O</smiles>

Naringenin $(\mathrm{R} 1=\mathrm{OH})$<smiles>[R]c1cc(O)c2c(c1)O[C@H](c1ccc(OC)c(O)c1)CC2=O</smiles><smiles>[R]c1cc(O)c2c(c1)OC(c1ccc(O)c(O)c1)CC2=O</smiles>

Eriodictyol $(\mathrm{R} 1=\mathrm{OH})$<smiles>[R]c1cc(O)c2c(c1)O[C](c1ccc(OC)cc1)CC2=O</smiles>

Glycosides
Narirutin

$\mathrm{R} 1$ = rutinoside

Naringin

$\mathrm{R} 1=$ neohesperidoside

Hesperidin

$\mathrm{R} 1$ = rutinoside

Neohesperidin

$\mathrm{R} 1=$ neohesperidoside

Eriocitrin

$\mathrm{R} 1=$ rutinoside

Neoeriocitrin

$\mathrm{R} 1=$ neohesperidoside

Didymin (Neoponcirin)

$\mathrm{R} 1$ = rutinoside

Poncirin

$\mathrm{R} 1=$ neohesperidoside

Fig. 3. Some common flavanone aglycones and their respective glycosides.

industrial use of large quantities of Citrus fruit, especially for the production of juice, results in the accumulation of huge amounts of by-products such as peels, seeds, cell and membrane residues, which account for about half of the fruit weight. These by-products can be used for the production of molasses, pectins, essential oils, limonene and cattle feed (Bocco et al., 1998; Jeong et al., 2004; Li et al., 2006a, 2006b). In addition, Citrus by-products are a good source of phenolic compounds, especially the characteristic flavanone glycosides, mainly naringin, hesperidin, narirutin, and neohesperidin. Currently, extraction of phenolic compounds from Citrus peels has attracted considerable scientific interest with aim to use them as natural antioxidants mainly in foods to prevent the oxidative alteration of lipids (Anagnostopoulou et al., 2006; Peschel et al., 2006; Zia-ur-Rehman, 2006). Indeed, cheap plant extracts rich in antioxidants could replace synthetic additives such

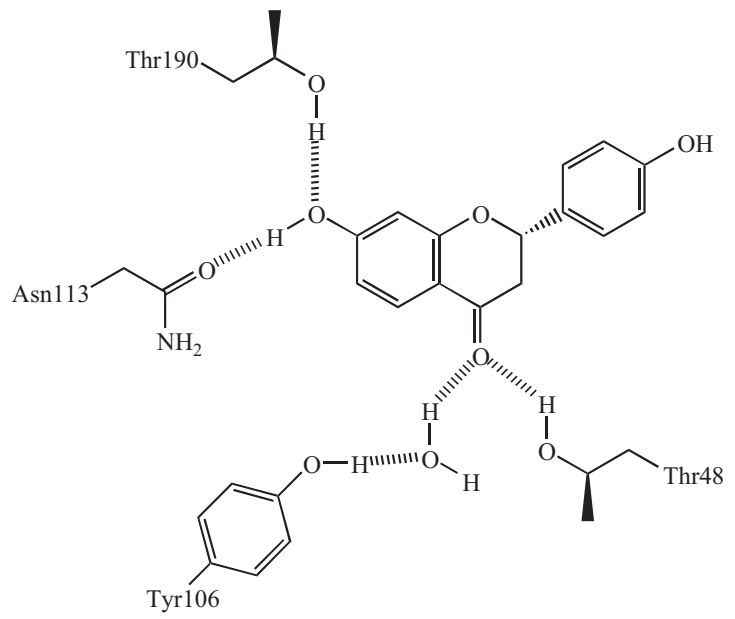

Fig. 4. The hydrogen bond network in the $(S)-4^{\prime}, 7$-dihydroxyflavanone-chalcone isomerase complex.

Adapted from Jez et al. (2002b) as butylated hydroxyanisole (BHA) and butylated hydroxytoluene (BHT), which might be toxic (Moure et al., 2001), in particular damaging to the liver and carcinogenic (Ak and Gülçin, 2008).

Up to now, several conventional and innovative extraction techniques have been reported for the extraction of phenols from Citrus by-products (Table 2). The most common method used is maceration in solvents (Anagnostopoulou et al., 2006; Jeong et al., 2004; Li et al., 2006a; Manthey and Grohmann, 1996; Xu et al., 2007; Zia-ur-Rehman, 2006), which is also considered suitable at scaledup level (Peschel et al., 2006). However, this extraction technique generally requires high temperatures $\left(50-150^{\circ} \mathrm{C}\right)$, long extraction times (up to several hours) and high polarity solvents like water and ethanol. Different types of solvent extraction techniques have been developed: hot water extraction (Xu et al., 2008), alkaline extraction (Bocco et al., 1998; Curto et al., 1992), extraction assisted by resins (Calvarano et al., 1996; Kim et al., 2007a), enzymes (Li et al., 2006b), electron beam and $\gamma$-irradiation (Kim et al., 2008; Oufedjikh et al., 2000). However, common drawbacks remain the degradation of the targeted compounds due to high temperature and long extraction periods and, more specifically, restrictive safety criteria (extraction under irradiation) and problems of enzyme denaturation. Supercritical fluid extraction (SFE) is a mild and efficient technique that has been little studied for the extraction of the phenolic compounds from Citrus by-products (Giannuzzo et al., 2003; Yu et al., 2007), possibly because of its higher costs in comparison to other innovative techniques.

With the increasing energy prices and environmental concern, chemical and food industries are challenged to find new technologies in order to reduce energy consumption, meet legal requirements on $\mathrm{CO}_{2}$ emissions, product/process safety and control, and increase quality as well as functionality. Separation technology (such as extraction, distillation, and crystallization) is one of the promising fields that could contribute to sustainable growth of chemical and food industries. For example, existing extraction technologies have considerable technological and scientific bottlenecks to overcome: often requiring up to $50 \%$ of 
Version définitive du manuscrit publiée dans / Final version of the manuscript published in :

Journal of Food Composition and Analysis (2014),vol 33, p 85-104, DOI: 10.1016/j.jfca.2013.11.004

Journal homepage: www.elsevier.com/locate/jfca

Table 1

Flavanone glycosides in different plant varieties and their products.

\begin{tabular}{|c|c|c|c|c|c|c|c|c|c|c|}
\hline \multirow[t]{2}{*}{ No. } & \multirow[t]{2}{*}{ Plant type } & \multicolumn{8}{|c|}{ Flavanone contents (mg aglycone/100g juice or edible fruit (without rind, pith and seeds)) } & \multirow[t]{2}{*}{ References } \\
\hline & & Narirutin & Naringin & Hesperidin & Neohesperidin & Eriocitrin & Neoeriocitrin & Didymin & Poncirin & \\
\hline 1 & $\begin{array}{l}\text { Black Sorghums } \\
\text { (Sorghum bicolor) grains }{ }^{c}\end{array}$ & $\begin{array}{l}53 \\
\text { (Aglycone) }\end{array}$ & - & - & - & $\begin{array}{l}66 \\
\text { (Aglycone) }\end{array}$ & - & - & - & Dykes et al. (2013) \\
\hline 2 & $\begin{array}{l}\text { Clementine } \\
\text { (Citrus clementina) juice }^{\mathrm{b}}\end{array}$ & 46.4 & 0.8 & 399 & - & - & - & - & - & $\begin{array}{l}\text { Dhuique-Mayer et al. (2005) } \\
\text { and Gattuso et al. (2007) }\end{array}$ \\
\hline 3 & Defatted olive & - & - & $8.01 \%$ & - & - & - & - & - & Alu'datt et al. (2013) \\
\hline 4 & Defatted soybean & - & - & $17.21 \%$ & - & - & - & - & - & Alu'datt et al. (2013) \\
\hline 5 & Grapefruit (C. paradisi) & 29.4 & 84 & 2.4 & 2.92 & - & - & 1.42 & 1.92 & $\begin{array}{l}\text { Peterson et al. (2006b) and } \\
\text { Igual et al. (2013) }\end{array}$ \\
\hline 6 & Grapefruit (C. paradisi) juice ${ }^{\mathrm{b}}$ & 76 & 230 & 9.3 & 12.1 & 4.1 & 3.2 & 3.0 & 12.6 & Gattuso et al. (2007) \\
\hline 7 & Grapefruit (C. paradisi) jam & 20 & 84 & 1.72 & 2.64 & - & - & 1.16 & 0.6 & Igual et al. (2013) \\
\hline 8 & Grapefruit red and pink & 3.34 & 13.87 & 0.27 & 0.42 & - & - & - & - & Peterson et al. (2006b) \\
\hline 9 & Grapefruit white & 5.36 & 16.90 & 3.95 & 0.25 & 0.16 & 0.05 & 0.09 & 0.20 & Peterson et al. (2006b) \\
\hline 10 & Lemon (C. limon) & 0.80 & 0.18 & 15.78 & - & 9.46 & - & 0.17 & - & $\begin{array}{l}\text { Peterson et al. ( } 2006 \mathrm{~b}) \text { and } \\
\text { González-Molina1 et al. } \\
\text { (2010) }\end{array}$ \\
\hline 11 & Lemon (C. limon) juice ${ }^{\mathrm{b}}$ & 3.8 & - & 205 & 14.5 & 167 & - & - & - & Gattuso et al. (2007) \\
\hline 12 & $\begin{array}{l}\text { Lemon (Citrus limetta Risso) } \\
\text { juice Mediterranean }^{\mathrm{b}}\end{array}$ & - & - & 4.29 & - & 2.10 & - & - & - & Barreca et al. (2011) \\
\hline 13 & Lime (Citrus latifolia) & 0.23 & - & 15.64 & - & 1.38 & 0.04 & - & - & Peterson et al. (2006b) \\
\hline 14 & $\begin{array}{l}\text { Lime juice } \\
\text { (Citrus latifolia) Mexican }\end{array}$ & - & - & 386 & - & - & - & 44.14 & - & Patil et al. (2009) \\
\hline 15 & Mandarin (C. reticulata) & 2.70 & - & 19.26 & - & 0.02 & - & 1.11 & - & Peterson et al. (2006a) \\
\hline 16 & $\begin{array}{l}\text { Mandarin } \\
\text { (Citrus reticulata) juice }^{\mathrm{b}}\end{array}$ & 39.2 & - & 243 & - & 3.1 & 0.5 & 14.4 & - & $\begin{array}{l}\text { Dhuique-Mayer et al. (2005) } \\
\text { and Gattuso et al. (2007) }\end{array}$ \\
\hline 17 & $\begin{array}{l}\text { Mandarin } \\
\text { (C. reticulata) young }^{\mathrm{f}}\end{array}$ & 43.9 & - & 261 & - & - & - & - & - & Ye et al. (2011) \\
\hline 18 & $\begin{array}{l}\text { Shiikuwasha } \\
\text { (C. depressa) } \text { peel }^{\mathrm{a}}\end{array}$ & 39.18 & 11.88 & 467.31 & 5.16 & - & - & - & - & Asikin et al. (2012) \\
\hline 19 & $\begin{array}{l}\text { Sour orange } \\
\text { (C. aurantium) }\end{array}$ & 0.08 & 18.83 & 0.00 & 11.09 & 0.53 & 14.01 & 2.89 & - & Peterson et al. (2006a) \\
\hline 20 & $\begin{array}{l}\text { Sour orange } \\
\text { (C. aurantium) } \\
\text { juice }^{\mathrm{b}}\end{array}$ & - & 19.7 & - & 8.7 & - & 7.7 & - & 7.3 & Gattuso et al. (2007) \\
\hline 21 & $\begin{array}{l}\text { Sweet orange } \\
\text { (C. sinensis Valencia) } \\
\text { Cyprus }^{\mathrm{d}}\end{array}$ & 787 & 13 & 6024 & - & - & - & - & - & $\begin{array}{l}\text { Goulas and Manganaris } \\
\text { (2012) }\end{array}$ \\
\hline 22 & $\begin{array}{l}\text { Sweet Orange } \\
\text { (Citrus sinensis) } \\
\text { Mauritian }\end{array}$ & 16.77 & - & 19.93 & - & - & 1.07 & 2.70 & 0.12 & Ramful et al. (2011) \\
\hline 23 & $\begin{array}{l}\text { Sweet orange } \\
\text { (C. sinensis Valencia) }\end{array}$ & 2.33 & 0.17 & 15.25 & - & 0.28 & 0.04 & 0.45 & - & Peterson et al. (2006a) \\
\hline 24 & $\begin{array}{l}\text { Sweet orange } \\
\text { (C. sinensis Valencia) } \\
\text { juice }^{\mathrm{b}}\end{array}$ & 51.4 & - & 257 & - & - & - & 18.9 & 3.1 & $\begin{array}{l}\text { Dhuique-Mayer et al. (2005) } \\
\text { and Gattuso et al. (2007) }\end{array}$ \\
\hline 25 & $\begin{array}{l}\text { Sweet Orange } \\
\text { (Citrus sinensis L. var. } \\
\text { Navel late) } \\
\text { fermented juice }^{\mathrm{b}}\end{array}$ & 413 & - & 311 & - & - & - & 60.9 & - & Escudero-López et al. (2013) \\
\hline 26 & Tangelo & 2.42 & 5.60 & 4.21 & 13.56 & 1.69 & 1.11 & 0.60 & - & Peterson et al. (2006a) \\
\hline 27 & Tangor & 7.10 & - & 15.42 & - & 1.01 & 1.77 & - & - & Peterson et al. (2006a) \\
\hline 28 & Thymus Pulegioides $^{\mathrm{c}}$ & $\begin{array}{l}24.64 \\
\text { (Aglycone) }\end{array}$ & - & - & - & $\begin{array}{c}3.01 \\
\text { (Aglycone) }\end{array}$ & - & - & - & Boros et al. (2010) \\
\hline 29 & $\begin{array}{l}\text { Tomato } \\
\text { (Lycopersicon esculentum) }\end{array}$ & $\begin{array}{c}18.18 \\
\text { (Aglycone) }\end{array}$ & - & - & - & - & - & - & - & $\begin{array}{l}\text { Slimestad et al. (2008) and } \\
\text { Harnly et al. (2006) }\end{array}$ \\
\hline
\end{tabular}

a $\mathrm{mg} / 100 \mathrm{~g}$ fresh flavedo weight.

b $\mathrm{mg} / \mathrm{L}$.

c $\mu \mathrm{g} / \mathrm{g}$.

d $\mu \mathrm{g} / \mathrm{g}$ dry matter.

e $\mathrm{mg} / \mathrm{g}$ fresh weight.

f $\mathrm{mg} / \mathrm{g}$ dry weight.

investments in a new plant and more than $70 \%$ of total process energy used in food, chemical and pharmaceutical industries. These shortcomings have led to investigating new "green" extraction techniques, aimed at sparing energy and reducing costs, such as microwave- or ultrasound-assisted extraction, ultrafiltration, flash distillation and controlled pressure drop processing (Chemat et al., 2009). Among them, ultrasound-assisted extraction (UAE) has been studied in details for the preparation of flavanone-rich extracts from Citrus by-products.

With the development of the "Green Chemistry" concept during the past few years, environment-friendly techniques are becoming more and more attractive. The extraction of bioactive compounds under ultrasound irradiation $(20-100 \mathrm{kHz})$ is one of the upcoming extraction techniques that can offer high reproducibility in shorter times, simplified manipulation, reduced solvent consumption and temperature and lower energy input (Chemat et al., 2008). During sonication, the cavitation process causes the swelling of cells or the breakdown of cell walls, thereby permitting high diffusion rates across the cell wall in the first case or a simple washing-out of the cell contents in the second (Vinatoru, 2001). It is known that the bursting of tiny cavitation bubbles may result in local temperature and pressure as high as $5000{ }^{\circ} \mathrm{C}$ and $1000 \mathrm{~atm}$, respectively. However, 
Version définitive du manuscrit publiée dans / Final version of the manuscript published in :

Journal of Food Composition and Analysis (2014),vol 33, p 85-104, DOI: 10.1016/ị.jfca.2013.11.004

Journal homepage: www.elsevier.com/locate/jfca

\section{Table 2}

Extraction and analysis of flavanone contents from various plant sources.

\begin{tabular}{|c|c|c|c|c|c|}
\hline Plant part & Extraction & Flavanones studied & Analytical technique & Comments & References \\
\hline $\begin{array}{l}\text { Sweet orange } \\
\quad \text { (Citrus sinensis) peel }\end{array}$ & Soxhlet extraction & Hesperidin, TPC & $\begin{array}{l}\text { 2D-TLC ( } 80: 20: 40 \text {, ethyl } \\
\text { acetate:acetic acid:water } \\
\text { and } 15 \% \text { acetic acid); Folin- } \\
\text { Ciocalteu test }\end{array}$ & $\begin{array}{l}\text { Methanolic fraction } \\
\text { with ethyl acetate } \\
\text { showed significant } \\
\text { TPC and RSA }\end{array}$ & $\begin{array}{l}\text { Anagnostopoulou } \\
\text { et al. (2006) }\end{array}$ \\
\hline $\begin{array}{l}\text { Satsuma mandarin } \\
\text { (C. unshiu Marc.) peel }\end{array}$ & $\begin{array}{l}\text { Ultrasound- } \\
\text { assisted extraction } \\
\text { (UAE) }\end{array}$ & $\begin{array}{l}\text { Narirutin, } \\
\text { hesperidin }\end{array}$ & $\begin{array}{l}\text { HPLC }(\text { RP C18 column } \\
(250 \mathrm{~mm} \times 4.6 \mathrm{~mm}, 5 \mu \mathrm{m}) \\
4 \% \text { acetic acid } / 100 \% \\
\text { methanol }(80: 20, \mathrm{v} / \mathrm{v}))\end{array}$ & $\begin{array}{l}\text { UAE can } \\
\text { significantly } \\
\text { enhance the } \\
\text { contents of } \\
\text { phenolic } \\
\text { compounds and } \\
\text { antioxidant } \\
\text { activities in } \\
\text { samples without } \\
\text { any intensive heat } \\
\text { treatment }\end{array}$ & Ma et al. (2008b) \\
\hline Clementines ( $C$. clementina) & $\begin{array}{l}\text { Solvent extraction } \\
\text { of } \gamma \text {-Irradiated } \\
\text { fruits }\end{array}$ & $\begin{array}{l}\text { Naringin, } \\
\text { hesperidin, } \\
\text { didymin, eriocitrin, } \\
\text { poncirin, and } \\
\text { neoeriocitrine }\end{array}$ & $\begin{array}{l}\text { HPLC }(\text { RP C1 } 18 \text { column } \\
(150 \mathrm{~mm} \times 4.5 \mathrm{~mm}, 5 \mu \mathrm{m}) \text {, } \\
4 \% \text { acetic acid } / 100 \% \\
\text { acetonitrile })\end{array}$ & $\begin{array}{l}\gamma \text {-Irradiation } \\
\text { stimulates PAL } \\
\text { activity and the } \\
\text { synthesis of } \\
\text { phenolic } \\
\text { compounds. Thus, } \\
\text { higher amounts of } \\
\text { flavanones are } \\
\text { obtained }\end{array}$ & $\begin{array}{l}\text { Oufedjikh et al. } \\
(2000)\end{array}$ \\
\hline $\begin{array}{l}\text { Grapefruit } \\
\quad \text { (C. paradisi Macf.) seeds }\end{array}$ & $\begin{array}{l}\text { Supercritical fluid } \\
\text { extraction }\end{array}$ & Naringin & $\begin{array}{l}\text { HPLC (Spherisorb ODS } \\
\text { column } \\
(250 \mathrm{~mm} \times 4.6 \mathrm{~mm}))\end{array}$ & $\begin{array}{l}\text { After experimental } \\
\text { design } \\
\text { implementation, } \\
\text { crucial factor } \\
\text { during extraction of } \\
\text { naringin was } \\
\text { pressure followed } \\
\text { by temperature }\end{array}$ & Yu et al. (2007) \\
\hline $\begin{array}{l}\text { Citrus juices of sweet } \\
\text { orange, tangerine, lemon } \\
\text { and grapefruit }\end{array}$ & $\begin{array}{l}\text { Solvent extraction } \\
\text { of freeze-dried } \\
\text { samples }\end{array}$ & $\begin{array}{l}\text { Eriocitrin, } \\
\text { narirutin, naringin, } \\
\text { hesperidin, } \\
\text { neohesperidin, and } \\
\text { didymin }\end{array}$ & $\begin{array}{l}\text { RP-HPLC, MS (one for the } \\
\text { MS }^{1} \text { full scan mode and } \\
\text { another for } \mathrm{MS}^{2} \text { ion } \\
\text { production scan mode) }\end{array}$ & $\begin{array}{l}\text { Most important } \\
\text { contribution of this } \\
\text { work is the } \\
\text { characterization of } \\
\text { flavanones using } \\
\text { HPLC-DAD-ESI- } \\
\text { CID-MS/MS }\end{array}$ & $\begin{array}{l}\text { Abad-Garcia et al. } \\
(2012)\end{array}$ \\
\hline Orange $(C$. sinensis) peel & $\begin{array}{l}\text { Instant controlled } \\
\text { pressure drop } \\
\text { (ICPD) technology } \\
\text { and UAE }\end{array}$ & $\begin{array}{l}\text { Naringin, } \\
\text { hesperidin }\end{array}$ & $\begin{array}{l}\text { HPLC }(\text { RP C18 column } \\
(250 \mathrm{~mm} \times 4 \mathrm{~mm}, 5 \mu \mathrm{m}) \\
0.5 \% \text { acetic acid and } 100 \% \\
\text { acetonitrile })\end{array}$ & $\begin{array}{l}\text { Peel by-products, } \\
\text { successively } \\
\text { treated by ICPD } \\
\text { (extraction of } \\
\text { essential oil) and } \\
\text { UAE gave extracts } \\
\text { richer in flavanones }\end{array}$ & Allaf et al. (2013) \\
\hline Tomato fruit & Solvent extraction & $\begin{array}{l}\text { Naringenin, } \\
\text { naringin }\end{array}$ & $\begin{array}{l}\text { HPLC (Chromolith } \\
\text { Performance RP-18e } \\
\text { column } \\
(100 \mathrm{~mm} \times 64.6 \mathrm{~mm}) \text {, } \\
50 \mathrm{mM} \text { phosphate buffer at } \\
\text { pH } 2.2 \text { /acetonitrile ( } 75: 25 \text {, } \\
\mathrm{v} / \mathrm{v}))\end{array}$ & $\begin{array}{l}\text { Faster analysis } \\
\text { owing to shorter } \\
\text { retention time of } \\
\text { prominent } \\
\text { flavonoids }\end{array}$ & Biesaga et al. (2009) \\
\hline $\begin{array}{l}\text { Spearmint (Mentha spicata L.) } \\
\text { leaves }\end{array}$ & $\begin{array}{l}\text { Supercritical } \\
\text { carbon dioxide (SC- } \\
\left.\mathrm{CO}_{2}\right) \text { extraction }\end{array}$ & Naringenin & $\begin{array}{l}\text { HPLC (RP C18 } \\
(25 \mathrm{~cm} \times 4.6 \mathrm{~mm}, 5 \mu \mathrm{m}) \text {, } \\
\text { TFA } 2.5 \mathrm{pH} \text { in deionized } \\
\text { water and } 100 \% \text { methanol })\end{array}$ & $\begin{array}{l}\text { Higher amount of } \\
\text { naringenin was } \\
\text { obtained by } \mathrm{SC}-\mathrm{CO}_{2} \\
\left(60^{\circ} \mathrm{C}, 200 \text { bars, }\right. \\
60 \mathrm{~min})\end{array}$ & Bimakr et al. (2011) \\
\hline Rio red grapefruits & Solvent extraction & $\begin{array}{l}\text { Narirutin, naringin, } \\
\text { neohesperidin, } \\
\text { didymin and } \\
\text { poncirin }\end{array}$ & $\begin{array}{l}\text { HPLC, LC-MS (ESI-, } \\
\text { capillary }\left(250^{\circ} \mathrm{C},-15 \mathrm{~V}\right) \text {, } \\
\mathrm{N} 2)\end{array}$ & $\begin{array}{l}\text { Optimized } \\
\text { parameters include } \\
\text { extraction } \\
\text { technique (MW vs } \\
\text { ultrasounds), } \\
\text { solvent, centrifugal } \\
\text { speed, } \\
\text { temperature, } \\
\text { sample to solvent } \\
\text { ratio, extraction } \\
\text { cycles, extraction } \\
\text { time and their } \\
\text { interactions }\end{array}$ & $\begin{array}{l}\text { Chebrolua et al. } \\
\text { (2011) }\end{array}$ \\
\hline
\end{tabular}


Version définitive du manuscrit publiée dans / Final version of the manuscript published in :

Journal of Food Composition and Analysis (2014),vol 33, p 85-104, DOI: 10.1016/j.jfca.2013.11.004

Journal homepage: www.elsevier.com/locate/jfca

Table 2 (Continued)

\begin{tabular}{|c|c|c|c|c|c|}
\hline Plant part & Extraction & Flavanones studied & Analytical technique & Comments & References \\
\hline C. unshiu peel & $\begin{array}{l}\text { Subcritical water } \\
\text { extraction }\end{array}$ & $\begin{array}{l}\text { Hesperidin, } \\
\text { narirutin }\end{array}$ & $\begin{array}{l}\text { HPLC, LC-MS (ESI+, } \\
\text { capillary }\left(350^{\circ} \mathrm{C}, 5.5 \mathrm{kV}\right) \text {, } \\
\mathrm{N} 2)\end{array}$ & $\begin{array}{l}\text { This environment } \\
\text { friendly technique } \\
\text { gave higher } \\
\text { amount of } \\
\text { flavanones in } \\
\text { comparison to } \\
\text { conventional one }\end{array}$ & Cheigh et al. (2012) \\
\hline C. reticulate peel & $\begin{array}{l}\text { Pressurised liquid } \\
\text { extraction (PLE) }\end{array}$ & Hesperidin & $\begin{array}{l}\text { LC-DAD-ESI/MS }(\text { ESI+, } \\
\left.\text { capillary }\left(350^{\circ} \mathrm{C}, 4 \mathrm{kV}\right)\right)\end{array}$ & $\begin{array}{l}\text { PLE compared with } \\
\text { UAE, Soxhlet and } \\
\text { heat-reflux } \\
\text { extractions }\end{array}$ & Li et al. (2012) \\
\hline Citrus juices and beverages & $\begin{array}{l}\text { Liquid-liquid } \\
\text { extraction }\end{array}$ & $\begin{array}{l}\text { Eriodictyol, } \\
\text { naringenin, } \\
\text { hesperetin, } \\
\text { eriocitrin, } \\
\text { narirutin, } \\
\text { hesperidin, } \\
\text { neoeriocitrin, } \\
\text { naringin, } \\
\text { neohesperidin, } \\
\text { didymin, poncirin }\end{array}$ & $\begin{array}{l}\text { UHPLC-ESI-MS/MS (RP C18 } \\
\text { column }(2.1 \mathrm{~mm} \times 50 \mathrm{~mm} \text {, } \\
2.6 \mu \mathrm{m}), \mathrm{H}_{2} \mathrm{O}(0.1 \% \mathrm{HCOOH}) \\
\text { and } \mathrm{CH}_{3} \mathrm{CN}, 0.3 \mathrm{~mL} / \mathrm{min} \text {, } \\
\text { Heated ESI+ spray voltage } \\
\left.\left(4.7 \mathrm{kV}, 270^{\circ} \mathrm{C}\right)\right)\end{array}$ & $\begin{array}{l}\text { A comprehensive } \\
\text { and throughput } \\
\text { assay of the } \\
\text { flavanones in citrus } \\
\text { juices using UPLC }\end{array}$ & Di Donna et al. (2013) \\
\hline $\begin{array}{l}\text { Cherry tomatoes, tomato sauce, } \\
\text { and tomato juice }\end{array}$ & $\begin{array}{l}\text { Liquid-liquid } \\
\text { extraction }\end{array}$ & Naringenin & $\begin{array}{l}\text { UHPLC-QqQ-MS (BEH C18 } \\
\text { column }(50 \mathrm{~mm} \times 2.1 \mathrm{~mm} \text {, } \\
1.7 \mu \mathrm{m}), 0.1 \% \text { formic acid } \\
\text { and acetonitrile, } 0.4 \mathrm{~mL} / \\
\text { min, ESI-, capillary } \\
\left.\left(-3.5 \mathrm{kV}, 400^{\circ} \mathrm{C}\right), \mathrm{N} 2\right)\end{array}$ & $\begin{array}{l}\text { An easy, fast, and } \\
\text { sensitive UPLC- } \\
\text { QqQ-MS method } \\
\text { was described to } \\
\text { identify and } \\
\text { quantify the most } \\
\text { abundant phenolic } \\
\text { compounds. }\end{array}$ & Di Lecce et al. (2013) \\
\hline Citrus mandarin pomace & $\begin{array}{l}\text { Microwave- } \\
\text { assisted extraction }\end{array}$ & $\begin{array}{l}\text { Naringenin, } \\
\text { naringin, } \\
\text { hesperidin }\end{array}$ & $\begin{array}{l}\text { HPLC (RP C18 column } \\
(4.6 \mathrm{~mm} \times 150 \mathrm{~mm}, 5 \mu \mathrm{m}) \text {, } \\
0.1 \% \text { formic acid, and } 100 \% \\
\text { methanol) }\end{array}$ & $\begin{array}{l}\text { Microwave } \\
\text { treatment as an } \\
\text { efficient process to } \\
\text { release bound } \\
\text { phenolic } \\
\text { compounds from } \\
\text { the plant matrix }\end{array}$ & Hayat et al. (2010) \\
\hline
\end{tabular}

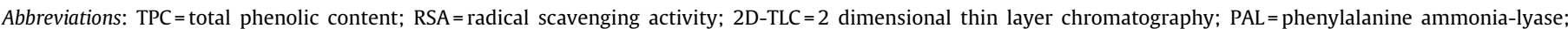

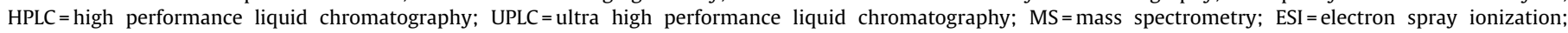
TFA $=$ trifluoroacetic acid.

these local energy bursts cannot significantly affect the bulk conditions as they are dissipated to the medium in very short periods of time (Luque-Garcia and Luque de Castro, 2003). UAE actually depends on the destructive effects of ultrasonic waves on solid matrices including plant materials. In addition to optimizing the solvent and temperature conditions, a better recovery of cell contents can be obtained by optimizing ultrasound frequency, sonication power and period, as well as the ultrasonic wave distribution (Wang and Weller, 2006). UAE has been applied recently to the extraction of hesperidin from Penggan (Citrus reticulata) peel (Ma et al., 2008a), phenolic acids and flavanone glycosides from Satsuma Mandarin (Citrus unshiu Marc) peel (Ma et al., 2008b, 2009) and total phenolic contents from Penggan peel (Ma et al., 2008c). In these works, methanol came up as a suitable extraction solvent to reach good yields. However, environmentally benign and non-toxic food grade organic solvents like ethanol, n-butanol and isopropanol are recommended by the US Food and Drug Administration for extraction purposes (Bartnick et al., 2006). Using ethanol, UAE was found more efficient for the extraction of polyphenols from orange peel wastes than conventional solvent extraction (Khan et al., 2010). Moreover, for the extraction of natural products, UAE gave higher yields than conventional techniques, not only at the lab-scale but also at the pilot-plant scale (Boonkird et al., 2008).

Recently, extraction of phenols from Citrus peels was successfully carried out under microwave irradiation (Hayat et al., 2009, 2010a, 2010b). Moreover, extraction of onion flavonoids without any added solvent has been developed using the technique of microwave hydrodiffusion and gravity (MHG) (Zill-e-Huma et al., 2009). In the process, extraction is initiated by the selective heating of the plant water content. MHG could also be used for the efficient extraction of flavanones from plant sources.
Natural extracts from Citrus by-products are rich in phenols that display in vitro antioxidant, antibacterial, antimicrobial, antiinflammatory and anticarcinogenic properties. As such, they could have a range of applications in the food, pharmaceutical and cosmetic industries. They could also appeal consumers due to their status of ingredients derived from natural sources without any chemical processing. One of the limiting factors in the market of natural extracts remains their significantly higher prices in comparison to synthetic additives. Natural extracts from food industry by-products could overcome this drawback due to the cheap starting material used. In addition, several studies have shown that natural extracts may exhibit higher biological activity than purified compounds, due to positive synergistic interactions between bioactive components (Gimenez-Bastida et al., 2009; Menichini et al., 2009; Sood et al., 2009, 2010).

For the determination of flavanone contents, spectrometric methods, which are fast and simple, are still used. However, they lack specificity for individual compounds. Generally, the ultraviolet spectra of flavanones and their glycosides show two strong absorption bands commonly referred to as band $A(330 \mathrm{~nm})$ and band $B(280 \mathrm{~nm})$. Band $A$ is associated with the B-ring in conjugation with the keto group while band $B$ is the typical absorption band of phenols and involves a strong contribution of A-ring. Substitutions on the A- or B-ring may produce hypsochromic or bathochromic shifts, which could be used for structural elucidation (Tsimogiannis et al., 2007).

The most efficient analytical techniques for flavanone identification and titration in extracts (see Table 2) are high or ultra high performance liquid chromatography (HPLC, UPLC) coupled with a diode array detector (DAD) and a mass spectrometer (Allaf et al., 2013; Bimakr et al., 2011; Cheigh et al., 2012). The development of 


\section{Journal homepage: www.elsevier.com/locate/jfca}

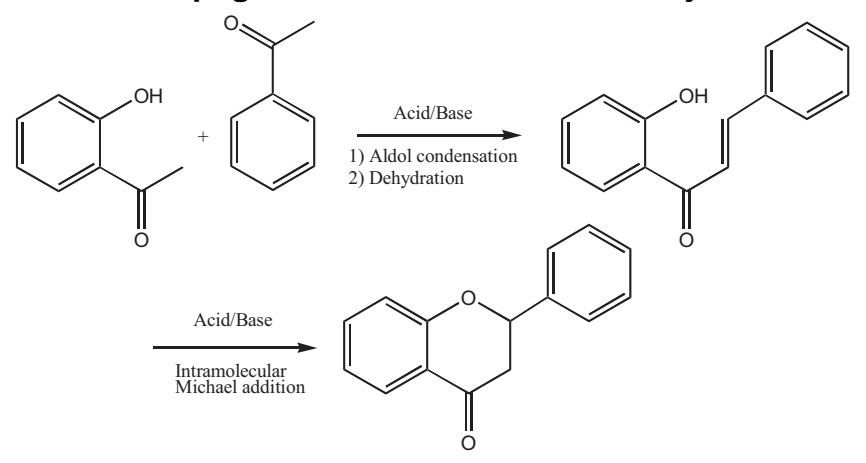

Fig. 5. Organic synthesis of flavanones.

UPLC has significantly enhanced the performance of separation by providing greater efficiency and drastically reducing analytical time (Di Donna et al., 2013; Di Lecce et al., 2013).

\section{Chemical synthesis of flavanones}

\subsection{Aglycones}

Up to now, the most common pathway for the synthesis of flavanone aglycones is the aldol condensation of 2-hydroxyacetophenones with benzaldehydes (Claisen-Schmidt aldol condensation)(Fig. 5). The reaction is usually performed under heating using acidic or alkaline conditions. The chalcones initially formed undergo cyclization to their respective flavanones under the same conditions (French et al., 2010; Krbechek et al., 1968; Shi et al., 2010). The condensation is still under study to develop efficient and environment-friendly conditions. For instance, strongly alkaline sodium hydroxide and ethoxide were replaced by Mg-Al hydrotalcites (Climent et al., 1995). Furthermore, different derivatives of chalcones and flavanones were also prepared by aldol condensation (Hsieh et al., 1998). Currently, the emphasis is on developing new catalysts that could be effective in aldol condensations and alternative methods (Chandrasekhar et al., 2005). Recently, the introduction of Li was shown to increase the surface basicity and catalytic activity of $\mathrm{MgO}$ in the synthesis of flavanone aglycones (Cortes-Concepcion et al., 2010).

\subsection{Chalcones}

The scarcity of flavanone chalcones in Nature is primarily due to their instability, as in neutral medium, 2'-hydroxychalcones undergo cyclization to the corresponding flavanones (intramolecular Michael addition). However, chalcones can be simply prepared by the reverse reaction (opening of the C-ring of flavanones) in strongly alkaline conditions. In such conditions, flavanone phenolate anions are first formed. Then, removal of a proton at $\mathrm{C} 2$ yields an enolate anion, from which the opening of the C-ring can take place with simultaneous formation of chalcone ions (Andújar et al., 2003). Fast acidification leads to the precipitation of the neutral chalcone, which can then be isolated by simple filtration. By contrast, in weakly basic conditions, chalcone phenolate anions undergo cyclization to flavanones through an enolate intermediate as described for naringin (González et al., 2002) and 2',6'dihydroxy-4,4'-dimethoxychalcone (Miles and Main, 1985).

\subsection{Glycosides}

The most prevalent flavanone derivatives in nature are 7-O- $\beta$ glycosides. The selective glycosylation of the most acidic C7$\mathrm{OH}$ group can be performed by protected glycosylbromide activated by silver carbonate (Oyama and Kondo, 2004). With some modifications, this method is still in use not only for glycosylation of phenolic compounds (Esaki et al., 1994) but also for glucuronidation (Moon et al., 2001). A simple route to flavanone $7-O-\beta$-D-glucoside is the partial hydrolysis of naringin and hesperidin using formic acid in cyclohexanol. However, the yields are low (ca. 10\%) (Fox et al., 1953). The enzymatic synthesis of flavanone glycosides was also described (Kometani et al., 1996) as well as the synthesis of naringin analogues bearing amino groups for use as scaffolds in drug discovery (Hanessian and Kothakonda, 2005) and metal-naringin complexes to increase the antioxidant and anti-inflammatory activities (Pereira et al., 2007).

\subsection{Glucuronides}

A better knowledge of the biochemical mechanisms by which dietary flavanones exert their potential health effects requires investigations on appropriate cell models (e.g., endothelial or smooth muscle cells) with the authentic circulating metabolites (of which glucuronides make the largest contribution) instead of the commercially available glycosides and aglycones that are frequently used as a first approach despite the limited biological significance. As an alternative to the expensive, inconvenient and low yielding extraction of conjugates from biological fluids, chemical synthesis appears as the most direct strategy to obtain substantial amounts of polyphenol metabolites for bioavailability and in vitro cell studies. In particular, there is a growing interest for the synthesis of polyphenol glucuronides as standards for identification and titration of in vivo metabolites and as biologically pertinent compounds for cell studies aiming at elucidating the potential health effects of polyphenols. Several works have been published about the chemical synthesis of polyphenol glucuronides.

For instance, the popular procedure, based on the Lewis acidactivated coupling of methyl-2,3,4-tri-O-acetyl-1-O-(trichloroacetimidoyl)- $\alpha$-D-glucuronate (Tomas-Barberan and Clifford, 2000) with partially protected polyphenols, was applied to the synthesis of isoflavone 7-O- $\beta$-D-glucuronides (Al-Maharik and Botting, 2006), quercetin 3-O- $\beta$-D-glucuronide (Needs and Kroon, 2006) and hydroxycinnamic acid $O-\beta$-D-glucuronides (Galland et al., 2008; Fumeaux et al., 2010).

Catechin $O-\beta$-D-glucuronides were also prepared with methyl2,3,4-tri-O-acetyl-1-O-bromo- $\alpha$-D-glucuronate as the glucuronyl donor (González-Manzano et al., 2009). Recently, the synthesis of a flavanone glucuronide (persicogenin $3^{\prime}-O-\beta$-D-glucuronide) was carried out with methyl-2,3,4-tri-O-acetyl-1-O-(trifluoroacetimidoyl)- $\alpha$-D-glucuronate, followed by a final deprotection step involving pig liver esterase (PLE) for the hydrolysis of the methyl ester of the glucuronyl residue (Boumendjel et al., 2009). A synthesis of quercetin 3-O- $\beta$-D-glucuronide was also performed by regioselective oxidation of the corresponding $3-O-\beta$-D-glucoside (phenolic $\mathrm{OH}$ groups protected as benzyl ethers) using TEMPO/NaOCl/NaBr under phase transfer conditions (Bouktaib et al., 2002). Recently, the synthesis of four flavanone glucuronides based on a regioselective protection of the flavanone nucleus was reported by our research group (Khan et al., 2010). In this work, glucuronides of naringenin ( $4^{\prime}-$ and 7-O- $\beta$-D-glucuronides) and hesperetin ( $3^{\prime}-$ and $7-O-\beta$-Dglucuronides), the major flavanone aglycones in grapefruit and orange respectively, were chemically synthesized (Fig. 6A and B). On the one hand, the most reactive hydroxyl group 7-OH was protected by selective benzoylation to allow subsequent glucuronidation of $4^{\prime}$ $\mathrm{OH}$ (naringenin) or 3'-OH (hesperetin) (B-ring). On the other hand, the selective debenzoylation at $7-\mathrm{OH}$ of the perbenzoylated flavanone aglycones allowed glucuronidation at the same position (A-ring). After careful deprotection, the target compounds were purified and characterized by nuclear magnetic resonance and mass spectrometry. So far, the synthesis of other less common flavanone 
(a)

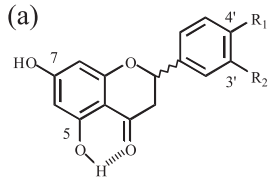
$\mathrm{R}_{1}=\mathrm{OH}, \mathrm{R}_{2}=\mathrm{H}: \mathbf{2 a}$
$\mathrm{R}_{1}=\mathrm{OMe}, \mathrm{R}_{2}=\mathrm{OH}: \mathbf{2 b}$

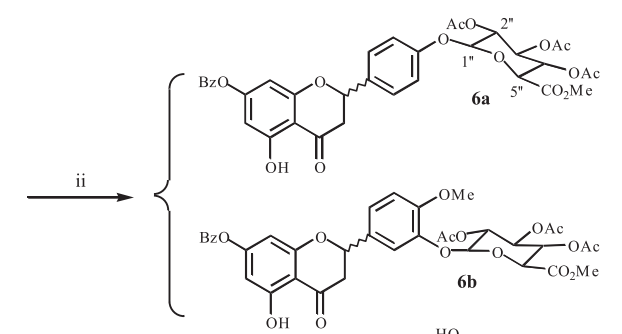

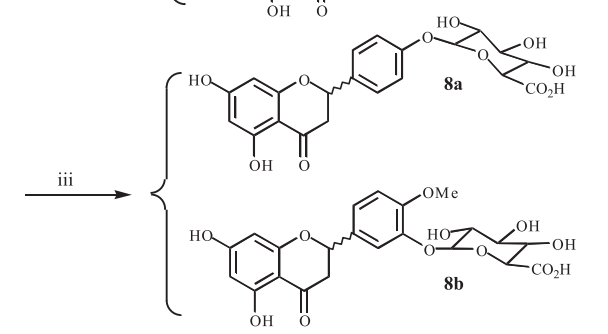

i) $\mathrm{BzCl}$ (1.1-1.5 equiv.), Pyridin ii) (1), $\mathrm{BF}_{3}-\mathrm{OEt}_{2}$ (2 equiv.), $\mathrm{CH}_{2} \mathrm{Cl}_{2}$ iii) $\mathrm{Na}_{2} \mathrm{CO}_{3}$ (1.2 equiv per ester group), $\mathrm{H}_{2} \mathrm{O} / \mathrm{MeOH}(2 / 5)$, then acidification to $\mathrm{pH} 6$ by Dowex resin $\left(\mathrm{H}^{+}\right.$form). (b)

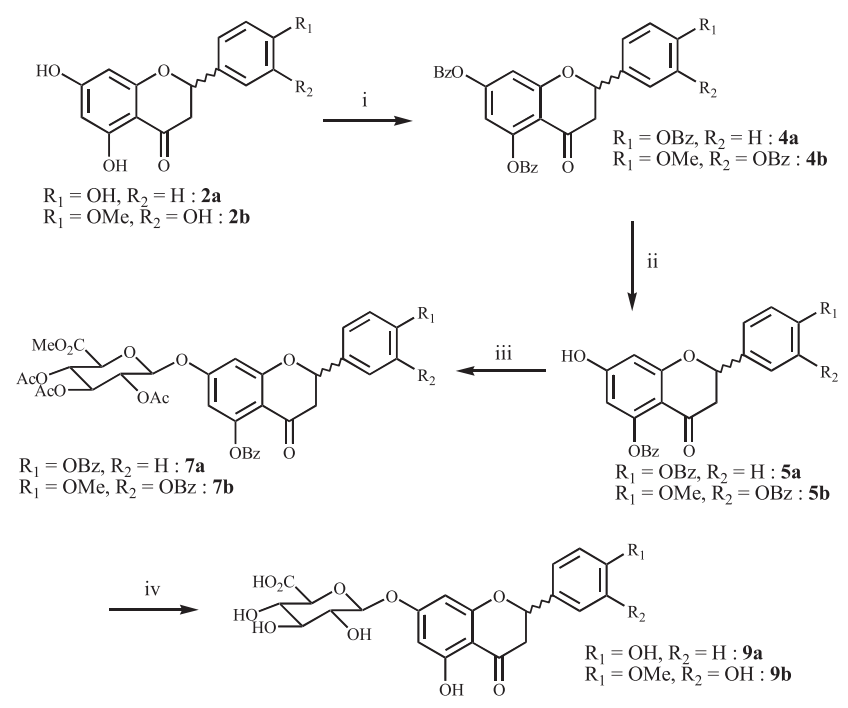

i) $\mathrm{BzCl}$ (excess), $\mathrm{NEt}_{3}, \mathrm{THF}, 0^{\circ} \mathrm{C}$ ii) $\mathrm{PhSH}$ (1 equiv.), imidazole, $\mathrm{NMP}$ iii) (1), $\mathrm{BF}_{3}-\mathrm{OEt}_{2}(2$ equiv.), $\mathrm{CH}_{2} \mathrm{Cl}_{2}$ iv) $\mathrm{Na}_{2} \mathrm{CO}_{3}$ (1.2 equiv. per ester group), $\mathrm{H}_{2} \mathrm{O} / \mathrm{MeOH}$ (2/5), then acidification to $\mathrm{pH} 6$ by Dowex resin $\left(\mathrm{H}^{+}\right.$form).

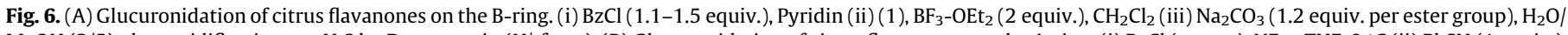

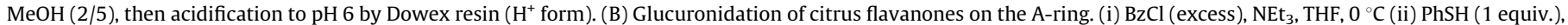
imidazole, $\mathrm{NMP}$ (iii) (1), $\mathrm{BF}_{3}-\mathrm{OEt}_{2}$ (2 equiv.), $\mathrm{CH}_{2} \mathrm{Cl}_{2}$ (iv) $\mathrm{Na}_{2} \mathrm{CO}_{3}$ (1.2 equiv. per ester group), $\mathrm{H}_{2} \mathrm{O} / \mathrm{MeOH}(2 / 5)$, then acidification to $\mathrm{pH} 6$ by Dowex resin ( $\mathrm{H}^{+}$form).

metabolites (diglucuronides, sulfoglucuronides, sulfates) has not been reported.

\section{Bioavailability of flavanones}

The oral bioavailability of a given nutrient describes its fate once ingested: release from food matrix (bioaccessibility, typically assessed in vitro, Bouayed et al., 2012), intestinal absorption, metabolism, transport in the general circulation, delivery to tissues and excretion. In spite of the high consumption of citrus fruits and juices worldwide, the bioavailability of flavanones is still incompletely known. Their daily intake has not been estimated in different populations but could be quite high compared with the average flavonol intake (25 mg/day) in several European countries (Manach et al., 2003). For instance, the mean dietary intake in Finland has been evaluated to be $8.3 \mathrm{mg} /$ day and $28.3 \mathrm{mg}$ /day for naringenin and hesperetin, respectively (Erlund, 2004; Manach et al., 2003).

After oral intake, flavanone glucosides and other glycosides are hydrolysed in the small intestine and in the colon, respectively, and the released aglycones are converted into their respective glucuronides, sulfates and sulfoglucuronides during their passage across the small intestine and liver. Finally, the bioactive forms (metabolites) are distributed through plasma at various cell sites and significant quantities can also be found in urinary excretions (Matsumoto et al., 2004). The fate of flavanones after ingestion is summarized in Fig. 7.

\subsection{Intestinal absorption}

Intestinal absorption involves the uptake from the intestinal lumen of nutrients into the intestinal epithelial cells, blood, lymph, or interstitial fluids. The study of pharmacokinetics in humans and animals can provide knowledge about the rate of absorption across the intestine. For instance, naringenin and its glucuronides were detected in the plasma and brain of rats (conjugation ratio four-time higher in plasma than in brain) only $10 \mathrm{~min}$ after naringenin administration $(20 \mathrm{mg} / \mathrm{kg}$ ) (Peng et al., 1998). The study was extended to determine the naringenin levels in rat brain, liver and bile using microdialysis coupled with a HPLC system. The results have shown a higher concentration of naringin in liver and bile (Tsai, 2002). To the best of our knowledge, the first report on the pharmacokinetics of flavanones in human subjects was published by Erlund and co-authors in 2001. After ingestion of orange or grapefruit juice ( $8 \mathrm{~mL} / \mathrm{kg}$ of body weight), the plasma concentration of hesperetin and naringenin aglycones was found in the range 0.6$6.0 \mu \mathrm{mol} / \mathrm{L}$, with a peak plasma concentration $\left(C_{\max }\right)$ of $6.0 \pm$ $5.4 \mu \mathrm{mol} / \mathrm{L}$ for naringenin from grapefruit juice and $2.2 \pm 1.6 \mu \mathrm{mol} / \mathrm{L}$ for hesperetin from orange juice. Moreover, elimination half-lives $\left(t_{1 / 2}\right)$ in the range of $1.3-2.2 \mathrm{~h}$ point to a relatively fast clearance from the general circulation. The percentage of flavanones excreted in urine (5$30 \%$ of total amount ingested) was lower than that of their absorption, which suggests a substantial distribution to tissues for these phenolic compounds (Erlund et al., 2001). In another study involving six volunteers, ingestion of hesperetin and naringenin (135 mg of each) under fasting conditions resulted in their appearance as metabolites in blood plasma $20 \mathrm{~min}$ later. The $C_{\max }$ of $2.7 \mu \mathrm{mol} / \mathrm{L}$ for hesperetin and $7.4 \mu \mathrm{mol} / \mathrm{L}$ for naringenin was reached 4.0 and $3.5 \mathrm{~h}$ after ingestion, respectively (Kanaze et al., 2007).

Intestinal absorption varies according to glycoside concentration and flavanone structure. After ingestion of $1 \mathrm{~L}$ of orange juice containing $444 \mathrm{mg}$ of hesperidin and $96.4 \mathrm{mg}$ of narirutin, blood analysis over a $24 \mathrm{~h}$ led to $C_{\max }$ values for hesperetin and naringenin (after deconjugation) at $1.28 \pm 0.13 \mu \mathrm{mol} / \mathrm{L}$ and $0.20 \pm 0.04 \mu \mathrm{mol} / \mathrm{L}$, respectively. The levels of flavanones in urine were expressed as percentage of their intake and amounted to $7.87 \pm 1.69 \%$ for naringenin and $6.41 \pm 1.32 \%$ for hesperetin. The relative urinary excretion of flavanones was not significantly affected by the dose ingested (Manach et al., 2003). In another study, high naringenin concentrations of $128 \pm 2 \mu \mathrm{M}, 144 \pm 8 \mu \mathrm{M}$ and $139 \pm 15 \mu \mathrm{M}$ were detected after $10 \mathrm{~h}$ in the plasma of rats fed 


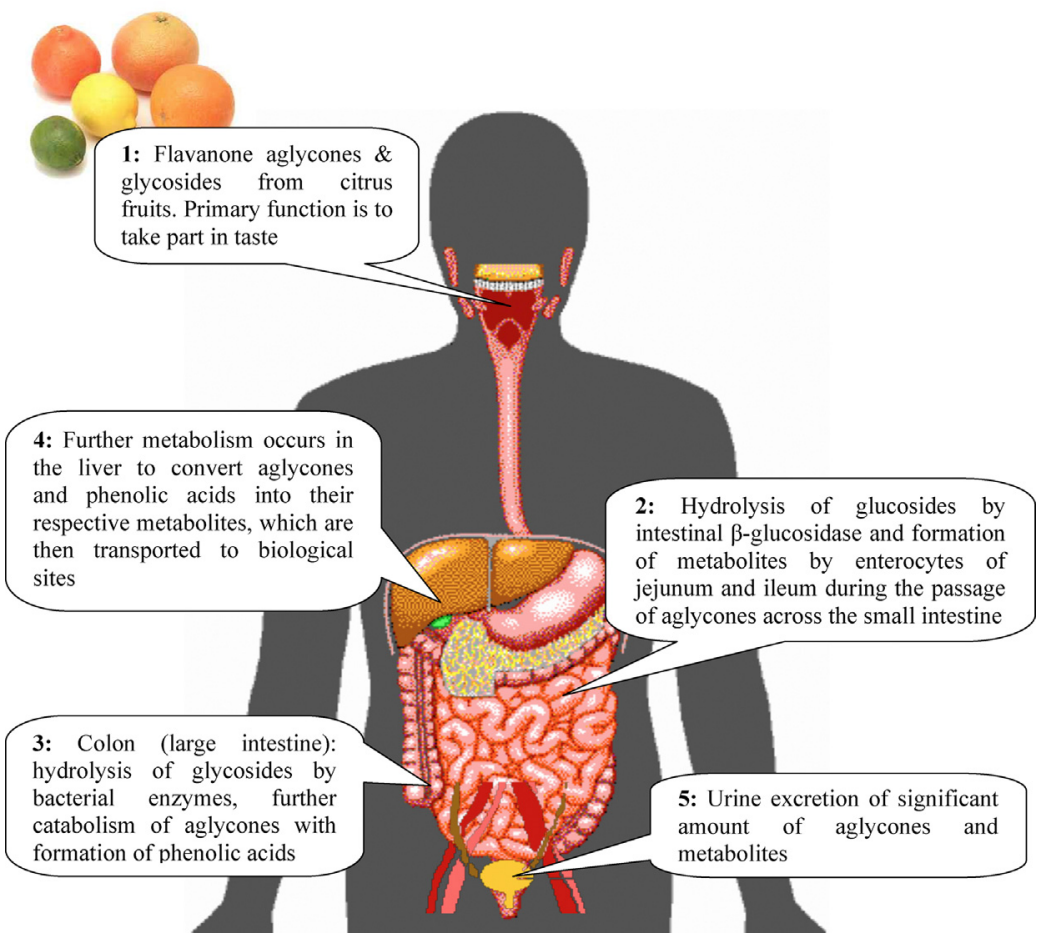

Fig. 7. Metabolic fate of flavanones.

with naringenin $(0.25 \%$ of total diet), naringenin-7- 0 - $\beta$-glucoside $(0.38 \%)$ and naringenin-7- 0 - $\beta$-rhamnoglucoside $(0.50 \%)$, respectively. The urinary excretion of naringenin was two times higher in rats fed with naringenin than in the ones fed with naringenin-7rhamnoglucoside (Felgines et al., 2000). Plasma and urine analyses pointed to naringenin being more bioavailable than hesperetin (Gardana et al., 2007; Kanaze et al., 2007). An in vitro hydrolysis showed a faster hydrolysis rate for hesperidin and narirutin (flavanone rutinosides) than for naringin and neohesperidin (flavanone neohesperiosides) (Wang et al., 2008). More recently, the same group studied the bioavailability of hesperetin and naringenin after the consumption of Citrus aurantium L. and Citrus sinensis Osbeck. These citrus varieties are used in the formulation of Zhi Zhu Wan, a traditional Chinese medicine used for the treatment of functional dyspepsia. The $T_{\max }$ (time to reach $C_{\max }$ ) of hesperetin was found at 3.7 and $8.5 \mathrm{~h}$ after the oral administration of $C$. aurantium and $C$. sinensis, respectively, which probably reflects differences in the structure and environment of the hesperetin glycosides depending on the source (Cao et al., 2010).

The permeability of epithelial cells to flavanones is also a good determinant of their intestinal absorption. Flavanones are transported from apical side (gut lumen) to basolateral side (blood). In in vitro models, hesperetin (aglycone) was found to be efficiently absorbed across Caco- 2 cell monolayers in comparison to hesperidin (hesperetin glycoside). The absorption mechanisms involved transcellular passive diffusion along with a newly proposed mechanism of proton-coupled active transport (Kobayashi et al., 2008). The study was further elaborated to explain the $\mathrm{H}^{+}$-driven polarized absorption and similar mechanisms were found for naringenin and eriodictyol aglycones (Kobayashi and Konishi, 2008). The faster absorption of flavanone aglycones compared to flavanone glycosides was confirmed for eriodictyol and eriocitrin in humans (Miyake et al., 2006). The transportation of flavonoids across the cell membranes involves ATP-binding cassette (ABC) transporters, which are present in the apical (lumen side) or basolateral (blood circulation side) membrane of enterocytes and facilitate excretion back into the intestinal lumen or uptake into the blood, respectively. Intestinal $\mathrm{ABC}$ transporters that have been related to flavonoid transport include P-glycoprotein (Pgp/MDR1/ABCB1), multidrug resistance proteins (MRPs/ABCCs), and breast cancer resistance protein (BCRP/ABCG2), of which Pgp, MRP2, and BCRP are localized in the apical membrane. A study on hesperetin metabolism in Caco-2 monolayers has shown that hesperetin 7-O- $\beta$-D-glucuronide and 7$O$-sulfate are predominantly transported to the apical side. By contrast, hesperetin aglycone also permeates to the basolateral side of the Caco-2 cell monolayer. The pattern of inhibition by different $A B C$ transporter inhibitors suggests that the apical efflux of hesperetin metabolites mainly involves BCRP. Altogether, these findings elucidate a novel pathway of hesperetin metabolism and transport and show that BCRP-mediated transport could be one of the main limiting steps for hesperetin bioavailability (Brand et al., 2008). The work was further elaborated to distinguish between the $(2 R)$ - and (2S)-enantiomers of flavanones. It was found that the intestinal absorption of commercially available racemic flavanones was similar to that of the naturally predominant (2S)-enantiomers (Brand et al., 2010).

Still the missing part in most bioavailability studies is the availability of authentic conjugates for use as standards. Those conjugates are also very much needed for investigating the mechanisms of their bioactivity in cell models.

\subsection{Metabolism}

A great part of the bioavailability studies has been devoted to naringenin, hesperetin and their glycosides. Improvements in methods for analyzing flavanone metabolites in human plasma and urine have made possible to estimate flavanone bioavailability in humans. The first step in flavanone metabolism is the extensive deglycosylation of flavanone glycosides within the intestinal epithelium by human and bacterial enzymes like $\beta$-glucosidases, rhamnosidases, rutinosidases etc. (Fig. 8). Investigations in rats demonstrated that the deglycosylation of naringenin-7-O- $\beta$-Dglucoside occurred early in the small intestine (Choudhury et al., 1999) while that of naringenin-7-O- $\beta$-D-rhamnoglucosides occurred in the colon (large intestine). Indeed, naringenin conjugates (glucuronides and/or sulfates) appeared within $3 \mathrm{~h}$ in the plasma of 
Version définitive du manuscrit publiée dans / Final version of the manuscript published in :

Journal of Food Composition and Analysis (2014), vol 33, p 85-104, DOI: 10.1016/j.jfca.2013.11.004

Journal homepage: www.elsevier.com/locate/jfca

Small intestine

Colon

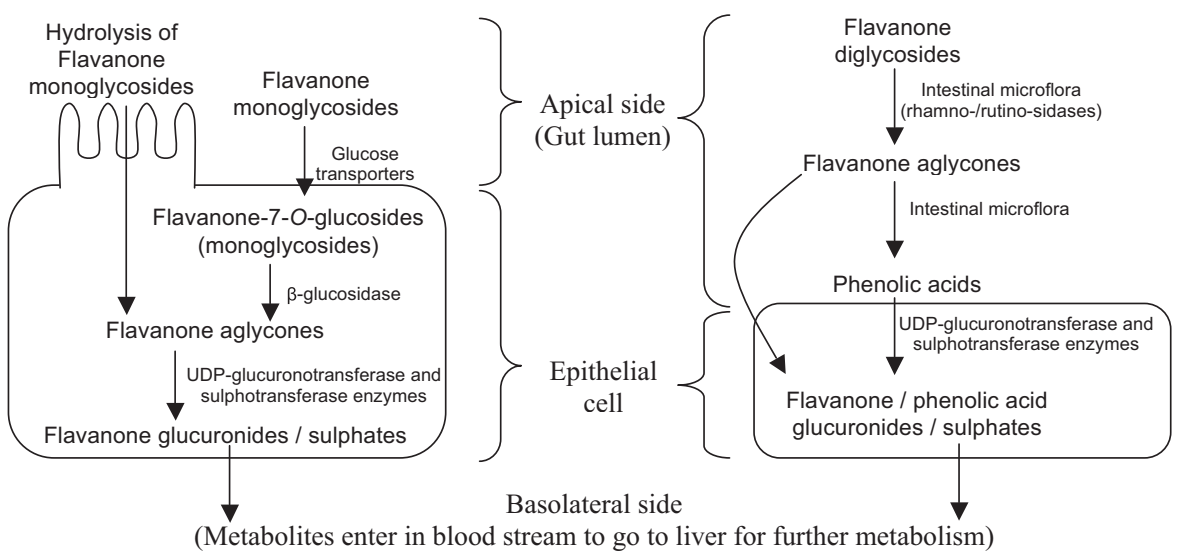

Fig. 8. Zoomed schematic presentation of flavanone metabolism in small and large intestine.

rats fed with naringenin or its $7-O-\beta$-D-glucoside whereas no naringenin metabolites were still detected in rats fed with naringenin-7- $O-\beta$-D-rhamnoglucoside. However, $10 \mathrm{~h}$ after ingestion, similar naringenin concentrations were found regardless of the diet, which clearly showed the delayed intestinal absorption of naringenin rhamnoglucosides (Felgines et al., 2000). It was confirmed in humans that hesperidin and naringin are absorbed in the distal part of the intestine (cecum). Once deglycosylated, the aglycones are glucuronated and/or sulfated during their transfer from the luminal side of the gut to the portal vein by the action of UDP-glucuronosyltransferase and sulfotransferase enzymes (Manach et al., 2003). In cecum, the intestinal microflora not only cleaves the glycosidic bonds but also degrades the aglycones into phenolic acids such as $p$-hydroxyphenylpropionic acid, $p$-coumaric acid, and p-hydroxybenzoic acid (Felgines et al., 2000; Manach et al., 2003). Likewise, eriocitrin (eriodictyol-7-O- $\beta$-D-rutinoside) is metabolized by intestinal microflora (Bacteroides distasomis or Bacteroides uniformis) to eriodictyol, which is then converted into 3,4-dihydroxycinnamic acid by Clostridium butyricum (Miyake et al., 2000). After intestinal absorption, aglycones and phenolic acids reach the liver, the main organ involved in flavanone metabolism, where further glucuronidation, sulfation, and in some cases methylation occurs, thus converting the rest of aglycones and phenolic acids into their respective metabolites. Due to lack of catechol groups in hesperetin and naringenin, no methylation by catechol-O-methyltransferase was observed, which is in contrast to catechin and quercetin (Felgines et al., 2000). By contrast, the conversion of eriodictyol to homoeriodictyol and hesperetin through methylation in liver was reported (Miyake et al., 2000).

Recently, a study was conducted to determine the effect of tumor on flavanone bioavailability. Similar naringenin concentrations were estimated in the liver and kidney of healthy and tumorbearing rats (Silberberg et al., 2006).

The impact of full-fat yogurt on the bioavailability and metabolism of orange flavanones in humans was investigated by analyzing plasma and urine over different intervals of time. Addition of yogurt into orange juice significantly reduced the quantity of flavanone metabolites excreted up to $5 \mathrm{~h}$ after ingestion. However, a statistical analysis over a longer time span (0-24 h) did not show any significant effect of yogurt addition (Mullen et al., 2008). Thus, it can be concluded that dairy food matrices may delay the intestinal absorption of flavanones with no impact on the overall bioavailability. Another study have shown that the quantity of flavanone metabolites excreted in urine after $24 \mathrm{~h}$ of orange juice intake has reduced about 7 times when juice is taken with yoghurt (Roowi et al., 2009). The authors proposed that this reduction was at the large intestine due to the alteration of flavanone metabolism by the microflora.

Flavanones appeared resistant to oxidation while their isomerization into chalcones (38-55\%) was significantly observed for the orange juice ( $\mathrm{pH} 7.5$ ). Moreover, the processing (pasteurization for 30 s at $95{ }^{\circ} \mathrm{C}$, freezing and Brix concentration to $60^{\circ}$ ) of orange juice showed no effect on the in vitro bioaccessibility of flavanones (GilIzquierdo et al., 2003). However, chalcones were found in higher quantities in industrially (vs. manually) pressed juice.

Glucuronidation and sulfation are the major conjugation pathways of flavanone aglycones. Structural studies of the plasma and urinary metabolites showed that the major metabolites of naringenin are naringenin-7- $O-\beta$-D-glucuronide, naringenin- $4^{\prime}-$ $O$ - $\beta$-D-glucuronide, naringenin- $4^{\prime}-O-\beta$-D-glucuronide-7- $O$-sulfate, naringenin-4'-O-sulfate-7-O- $\beta$-D-glucuronide and naringenin4',7-0-disulfate (Tripoli et al., 2007; Brett et al., 2009). Similarly, the main hesperetin conjugates are hesperetin-7-O- $\beta$-D-glucuronide, hesperetin-3'-O- $\beta$-D-glucuronide, hesperetin diglucuronide and sulfoglucuronide (Matsumoto et al., 2004; Mullen et al., 2008). Among all these metabolites, glucuronides largely prevail (87\%) but the importance of the other metabolites should not be underestimated (Manach et al., 2003). The position at which glucuronidation occurs might influence the resulting bioactivity including the antioxidant activity and affinity for specific proteins (Tripoli et al., 2007). Up to now, no data have been reported about the antioxidant activity of flavanone glucuronides. However, since the common flavanones hesperetin and naringenin are devoid of catechol group, which is the critical structural determinant of the antioxidant (reducing) activity for polyphenols, both are weak antioxidants and their glucuronides (with one less free phenolic $\mathrm{OH}$ group) are expected to be even less potent. It is thus quite likely that the bioactivity expressed by flavanone glucuronides is largely unrelated to their redox properties and rather reflects their interactions with specific proteins.

\section{Interaction of flavanones with human serum albumin}

In the past decade, studies exploring the possible health effects of flavanones were devoted to assess either their metabolism and bioavailability or their possible therapeutic value as potential drugs. Unfortunately, the delivery of the circulating flavanones and their metabolites to specific biological sites is still poorly documented. The interaction of flavonoids with human serum albumin (HSA) could be an important factor controlling their 


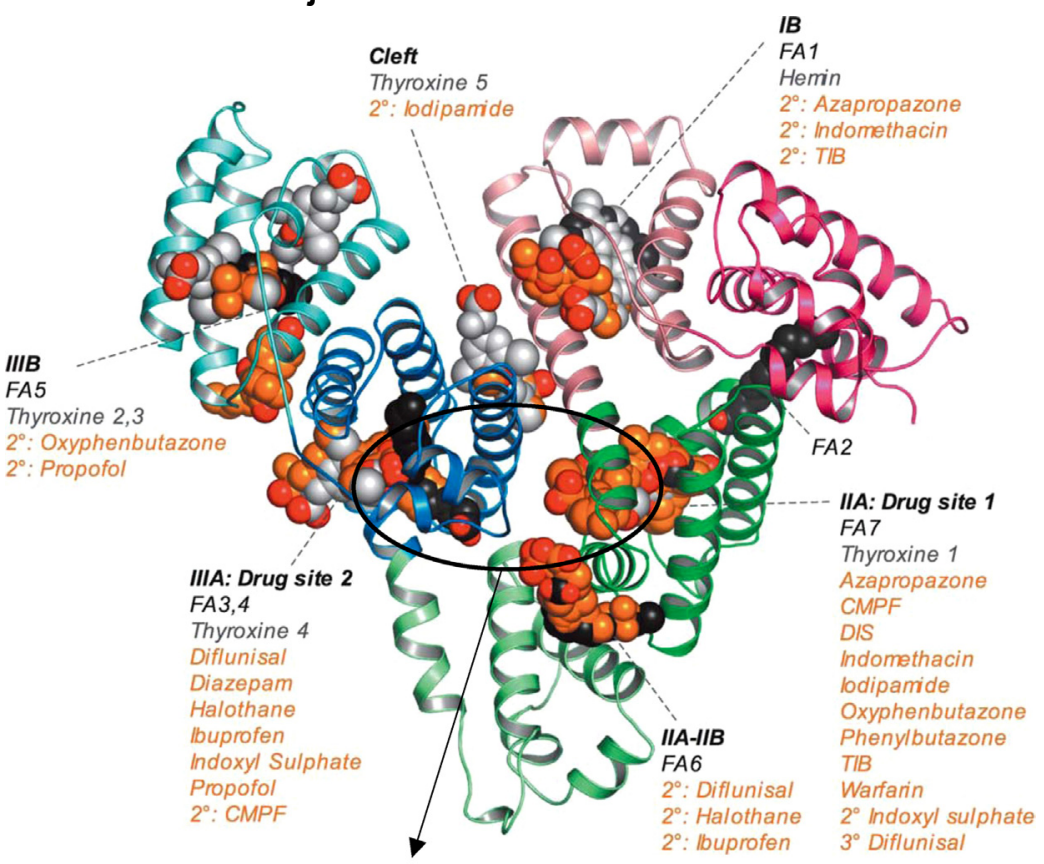

FIAAVANONE

Fig. 9. Three dimensional structure of HSA with common ligands bound at different binding sites. Adapted from Ghuman et al. (2005)

half-life in plasma and transport to biological sites. Indeed, serum albumin is the major protein of blood plasma with a concentration as high as $0.6 \mathrm{mM}$. The literature on the structural aspects and binding locations of HSA is well described by a number of comprehensive reviews (He and Carter, 1992; Sugio et al., 1999). Beside its role in the maintenance of colloidal osmotic blood pressure and bodily detoxification, HSA transports fatty acids and a large variety of drugs (Varshney et al., 2010) and food components including polyphenols (Dufour and Dangles, 2005) (Fig. 9). Interestingly, HSA has been shown to accumulate in solid tumors and in inflamed joints in arthritic disease and could thus encourage the specific delivery of drugs at those sites (Kratz, 2008).

A significant amount of the literature available on albuminflavonoid interactions reports not only quantitative thermodynamic data (binding constants), but also qualitative analyses aimed at locating the possible binding sites (Banerjee et al., 2008; Dufour and Dangles, 2005; Lu et al., 2007; Rawel et al., 2005). In particular, quercetin and its metabolites were studied for their affinity with HSA (Murota et al., 2007; Zsila et al., 2003). In addition to other conventional techniques, fluorescence spectroscopy is the analytical tool that is most widely used to investigate binding to HSA(Oravcová et al., 1996). Indeed, the single tryptophan residue of HSA (Trp214, site I) can be excited at $295 \mathrm{~nm}$ and emits fluorescence at $340 \mathrm{~nm}$. From the quenching of this fluorescence by a given ligand, the binding constant can be estimated (Sulkowska, 2002).

The affinity of flavanones to HSA has been more recently investigated. In an original study, piezoelectric quartz crystal impedance (PQCI) analysis was performed to measure the affinity of hesperidin for immobilized HSA. The association constant was estimated at $3.42 \mathrm{mg} \mathrm{ml}^{-1}$ using Scatchard analysis (Liu et al., 2004). The interaction of hesperidin with bovine serum albumin (BSA) was also investigated by fluorescence spectroscopy (Wang et al., 2007). Xie and co-authors used fluorescence spectroscopy with support of Fourier-transformed infrared (FT-IR) and UV-vis spectroscopies to determine the binding constant, binding site and binding mechanism of hesperetin to HSA. From the Stern-Volmer equation, a binding constant of about $81 \times 10^{3} \mathrm{M}^{-1}$ was estimated at $\mathrm{pH}$ 7.4. The $K$ value decreased with increasing the $\mathrm{pH}$ from 6.4 to 8.4 due to, (a) conformational changes in HSA which affect the shape of the hydrophobic binding cavities and (b) the increased dissociation of the phenolic hydroxyl groups of hesperetin. Moreover, FT-IR spectroscopy suggested that hesperetin binds to subdomain IIA (Xie et al., 2005a). The study was further extended to investigate the association of naringenin $\left(K=127 \times 10^{3} \mathrm{M}^{-1}\right)$ with HSA (Xie et al., 2005b). Conjugation of flavanone aglycones may affect their affinity for HSA. For instance, the binding constant of naringin, a naringenin diglycoside, was found lower $\left(K=18 \times 10^{3} \mathrm{M}^{-1}\right)$ than that of naringenin (Zhang et al., 2008). Moreover, the presence of metal ions in the medium may also reduce the affinity of flavanones for HSA (Hu et al., 2010). The main mechanisms involved in the interaction include the hydrophobic effect (van der Waals interactions between the ligand and hydrophobic amino acid residues with concomitant desolvation), electrostatic interactions between Lys residues and the flavanone phenolate ion, formed after deprotonation of the most acidic $\mathrm{OH}$ group at position $\mathrm{C}$, and hydrogen bonding between the phenolic $\mathrm{OH}$ and keto groups of hesperetin and the polypeptide chain or other polar amino acid residues (Xie et al., 2005a). Thermodynamic calculations (enthalpy change $\Delta H$, free energy change $\Delta G$, positive entropy change $\Delta S$ ) suggest that the electrostatic interactions are more effective in flavanone - HSA binding than other forces (Hu et al., 2010). Up to recently, the affinity for HSA of true circulating flavanone metabolites had not been investigated. Hence, our group studied the interaction of chemically synthesized flavanone glucuronides (main circulating metabolites in humans) with HSA (Khan et al., 2011). Compared with naringenin and hesperetin, it was noted that glucuronidation only weakly destabilizes the flavanone-HSA complexes, the effect being slightly stronger in the case of the B-ring glucuronidation. The investigations were further extended to flavanone chalcones, which proved better HSA ligands than their flavanone counterparts.

\section{Bioactivity of flavanones}

Over the past few decades, extensive research has been conducted on dietary compounds that could be protective against lethal diseases, in particular cardiovascular disease and cancers. 


\section{Journal homepage: www.elsevier.com/locate/jfca}

These potentially bioactive compounds include phytoestrogens, carotenoids, ascorbic acid, citrus limonoids, organosulfur compounds and a good number of polyphenols. The basic mechanisms implicated in the potential health effects of polyphenols are mainly the inhibition of lipid and DNA oxidation (antioxidant activity) and the regulation of gene expression (Kris-etherton et al., 2002; Patil et al., 2009). Like other polyphenols, flavanones are also studied for their effects on specific cells. However, the missing part remains the investigation of true flavanone metabolites. Examples of in vitro/in vivo studies conducted to explore the beneficial effects of flavanones and the mechanisms involved are discussed below.

\subsection{Radical-scavenging effects}

Reactive oxygen species (ROS)/reactive nitrogen species (RNS) in biological systems are typically unstable and produced in low concentration for physiological signaling pathways and in larger concentration (oxidative stress) to destroy viruses and bacteria in leucocytes during infection (inflammatory response). The chronic exposure to oxidative stress is considered an initiating event in the development of degenerative diseases (Brown and Borutaite, 2006; Forman et al., 2008). ROS/RNS include the superoxide anion $\left(\mathrm{O}_{2}{ }^{\bullet-}\right)$, hydrogen peroxide $\left(\mathrm{H}_{2} \mathrm{O}_{2}\right)$, the hydroxyl radical $\left(\mathrm{HO}^{\bullet}\right)$, the hypochlorite ion $\left(\mathrm{ClO}^{-}\right)$, nitrogen dioxide $\left(\mathrm{NO}_{2}\right)$ and peroxynitrite $\left(\mathrm{ONOO}^{-}\right)$, lipid oxyl and peroxyl radicals $\left(\mathrm{RO}^{\bullet}, \mathrm{ROO}^{\bullet}\right)$ produced during the autoxidation of polyunsaturated fatty acids. Phenolic compounds are extensively studied for their ability to reduce ROS/ RNS (antioxidant activity, AA), thereby preventing the oxidative damage they cause to the host's biomolecules.

The antioxidant activity of flavanones depends upon the number and spatial arrangement of phenolic $\mathrm{OH}$ groups (Cai et al., 2006; Sadeghipour et al., 2005). Up to now, in vitro and in vivo investigations have been performed to determine the antioxidant potential of flavanone aglycones, chalcones, and glycosides. No literature is available about the antioxidant capacity of flavanone glucuronides.

A comparative study on the antioxidant properties of nine different flavanones (naringin, neohesperidin, neoeriocitrin, hesperidin, narirutin, naringenin, hesperetin, eriodictyol and isosakuraternin) using the crocin bleaching inhibition assay showed that the presence of a catechol nucleus $\left(3^{\prime}, 4^{\prime}\right.$-dihydroxy substitution on the B-ring) and its $O$-methylation have no significant effect on the antioxidant activity (AA) of aglycones, which is surprising. By contrast, an increase in AA was observed with the glycosides having a catechol nucleus while $O$-methylation of the catechol has an opposite effect (Di Majo et al., 2005). O-Glycosylation often reduces the $\mathrm{AA}$, which points to the participation in the radicalscavenging reaction of the $\mathrm{OH}$ group involved in the glycosidic bond (Van Acker et al., 1996). The different glycosyl moieties may also have a small effect on AA. For instance, the glycosylation of hesperetin on the $\mathrm{C} 7-\mathrm{OH}$ group by neohesperidose affects the AA while the glycosylation by rutinose has no effect (Di Majo et al., 2005). While substitution on a hydroxyl group typically decreases the AA, addition of a hydroxyl group can strongly increase it. For example, $3^{\prime}, 5^{\prime}$-dihydroxynaringin (pyrogallol B-ring) is ca. 70 times as potent as naringenin (Ye et al., 2009). Flavanones present a higher AA in a hydrophilic environment. In a lipophilic environment, some flavanones (neohesperidin, hesperetin, isosakuranetin) showed a reduced antioxidant potential while others (naringin, narirutin, naringenin, neoeriocitrin, eriodictyol) even become pro-oxidant (Finotti and Di Majo, 2003). Overall, common dietary flavanones being devoid of a catechol nucleus are only poor antioxidants and their metabolites are expected to be even less potent. Hence, the most significant mechanisms involved in their health effects must be unrelated to their antioxidant activity.

\subsection{Anti-inflammatory effects}

The phenomena of inflammation have been well described in literature through many reviews. Inflammation is the most obvious manifestation of immune defense. It is manifested by swelling, pain, heat, and redness in the affected tissue and helps eliminate the sources of damage (viruses, bacteria) and initiate healing. Inflammation is produced by immune cells within the tissue, releasing specific mediators that control local circulation and cell activities (Silverstein, 2009). Inflammation response to external stimuli may arise from the action of amines (histamine and 5-hydroxytryptamine), short peptides (bradykinin), long peptides (interleukin-1 (IL1 )), lipids (prostaglandins (PGs) and leukotrienes (LTs)), and many regulatory enzymes (protein kinase $C$, phosphodiesterase, lipoxygenase, and cyclooxygenase) (Vane and Botting, 1987). Many of the chronic and uncured diseases that plague human populations are due to a dysfunctioning of the immune response.

Hesperidin (hesperetin 7-rutinoside) was found to inhibit kinases and phosphodiesterases responsible for cellular signal transduction and activation during an inflammation response (Manthey et al., 2001). An inhibitory effect of hesperidin on pleurisy (chronic inflammation of lungs) induced by carrageenan was investigated in rats. The results showed a reduction in the volume of exudates and the number of migrating leucocytes by $48 \%$ and $34 \%$, respectively, which makes hesperidin a mildly antiinflammatory agent. Furthermore, this research group observed that hesperidin can reduced yeast-induced hyperthermia in rats (Emim et al., 1994). In another study, hesperidin showed an inhibitory effect on lipopolysaccharide (LPS)-induced overexpression of cyclooxygenase-2, inducible nitric oxide synthase (iNOS), overproduction of prostaglandin E2 and nitric oxide (NO) (Sakata et al., 2003). Similar anti-inflammatory effects were also found for poncirin in RAW 264.7 macrophage cells (Kim et al., 2007b). A study also showed the anti-inflammatory activity of hesperidin by inhibiting arachidonic acid and histamine release (Galati et al., 1994). Significant literature also reports on the anti-inflammatory activity of naringenin and its glycosides. These flavanones are effective in the inhibition of pro-inflammatory cytokines induced by LPS in macrophages and ex vivo human whole-blood models to prevent periodontitis (Bodet et al., 2008). They also help attenuate LPS/interferon (IFN)- $\gamma$-induced tumor necrosis factor (TNF)- $\alpha$ production in glial cells by inhibiting iNOS expression and nitric oxide production, p38 mitogen-activated protein kinase (MAPK) phosphorylation and downstream signal transducer and activator of transcription-1 (STAT-1) to protect neuro-inflammatory injury (Vafeiadou et al., 2009). Finally, they aid in the reduced production of nitrate and nitrite (indicators of inflammatory process) in DSS (dextran sodium sulfate)-induced ulcerative colitis mice models to control the formation of intestinal edema (Amaro et al., 2009).

\subsection{Anti-cancer effects}

Advances in cancer research have been spectacular during the past decade. However, it is very unfortunate that the rate of cancer incidence is increasing at an alarming rate. A recent estimation in France has given the figure of 320,000 cases diagnosed in 2005, among which 180,000 in man and 140,000 in woman (INC report). It is clear that serious research in combating cancer is more than ever essential.

Cancer is a complex family of diseases. In terms of molecular and cell biology, cancer is a disease characterized by abnormal gene expression. This altered gene expression occurs through a number of mechanisms, including direct insults to DNA (such as gene mutations, translocations, or amplifications) and abnormal gene transcription or translation. When the DNA of normal cells is exposed to damaging substances (carcinogens), the cells may 


\section{Journal homepage: www.elsevier.com/locate/jfca}

undergo genetic alterations that result in malignant transformations, a process known as carcinogenesis. Carcinogens include chemical agents (from industrial pollutants, tobacco etc.), viruses (human papilloma virus, hepatitis B\&C virus), ionizing (X-rays) and ultraviolet radiations, particles (asbestos, wood dust) and many others. ROS (superoxide, hydrogen peroxide, hydroxyl radical) are also found major causes of not only DNA damage but also protein and lipid damages which lead to aging (Ames and Gold, 1998).

Unlike other flavonoids, flavanones have not been extensively studied for their anti-cancer activities. Moreover, the studies have remained limited to aglycones and glycosides. Recently, hesperetin 7-glucuronide (Hp7G) was demonstrated to affect osteoblast differentiation (Trzeciakiewicz et al., 2010). The major citrus flavanones can be effective in fighting carcinogenesis by minimizing DNA damage, tumor development and proliferation.

\subsubsection{Antimutagenic effects}

Flavanones can protect DNA damage by their capacity to absorb UV light. The results from a UV irradiated model of plasmidic DNA showed a considerable protecting effect of naringenin against UV-induced damage of DNA (Kootstra, 1994). The moderate antioxidant capacity of flavanones can also be useful in protecting against mutation by free radicals generated near DNA. Furthermore, naringin also inhibits $\mathrm{H}_{2} \mathrm{O}_{2}$-induced cytotoxicity and apoptosis, possibly via its effect on the $\mathrm{H}_{2} \mathrm{O}_{2}$-induced expression of an apoptosis-associated gene (Kanno et al., 2003). Naringenin may exhibit anti-mutagenic changes by stimulating DNA repair, following oxidative damage in human prostate cancer cells (Gao et al., 2006).

\subsubsection{Inhibition of tumor development}

The pharmacological importance of flavanones can also be evaluated by their action against tumor development. So et al. (1996) studied the effect of hesperetin and naringenin on the development of breast cancer induced by 7,12-dimethylbenz[a]anthracene in female rats. The results showed that tumor development was delayed in rats fed with an orange juice/naringin-supplemented diet (So et al., 1996). Later on, concerning the anti-angiogenic effect of flavanones, an enzyme-linked immunosorbent assay (ELISA) was used to measure the vascular endothelial growth factor (VEGF) release from mammary adenocarcinoma human breast cancer cells. Naringin appeared more potent than rutin, apigenin, kaempferol and chrysin (Schindler and Mentlein, 2006). 8-Prenylnaringenin, a derivative of naringenin, inhibits angiogenesis induced by basic fibroblast growth factor (VEGF) or the synergistic effect of two cytokines in combination, in an in vitro and in vivo study (Pepper et al., 2004). Eight flavanones, including flavanone, 2'-hydroxyflavanone, 4'-hydroxyflavanone, 6-hydroxyflavanone, 7-hydroxyflavanone, naringenin, naringin, and taxifolin, were investigated for their antitumor effects in colorectal carcinoma cells (HT29, COLO205, and COLO320HSR). 2'-Hydroxyflavanone came up as the most potent chemopreventive agent and thus showed a significant inhibitory effect on tumor formation. A recent study on hesperetin supplementation in male albino Wistar rats showed its inhibition of 1,2-demithylhydrazine (DMH)-induced colon carcinogenesis. The investigation suggested that hesperetin may inhibit phase I enzymes (involved in carcinogen activation), induce phase II xenobiotic metabolizing enzymes and scavenge the electrophilic carcinogenic species (Aranganathan et al., 2009).

\subsubsection{Anti-proliferation effects}

Naringenin was successfully investigated for its cell antiproliferation effect on an HT-29 colon cancer cell line. Cell proliferation measured by a colorimetric assay was significantly inhibited especially when HT-29 cells were exposed to naringenin at doses greater than $0.7 \mathrm{mM}$. The results suggested a potential role for citrus fruits as a source of chemoprotective agents against colon cancer
(Frydoonfar et al., 2003). In a comparative study, flavanones showed a significant anti-proliferative activity against lung, colon, breast, prostate and melanoma cancerous cell lines. Moreover, glycosylation reduced the anti-proliferative activity in both flavonoid classes (Manthey and Guthrie, 2002). A C2-C3 double bond seems important for the anti-proliferative activity of flavonoids and indeed flavones are typically more potent that flavanones (Agullo et al., 1996; Kawaii et al., 1999; Manthey and Guthrie, 2002; Rodriguez et al., 2002). Interestingly, methylation of hesperetin and eriodictyol at $\mathrm{C} 7-\mathrm{OH}$ increased the anti-proliferative capacity (BenaventeGarcía and Castillo, 2008). Several mechanisms have been put forward to explain the antiproliferative activity of flavonoids. The most accepted hypothesis is the inhibition of several kinases involved in signal transduction such as protein kinases $C$, tyrosine kinases, PI 3-kinases or S6 kinase (Casagrande and Darbon, 2001).

The effects of $17 \beta$-estradiol (E2) hormone cover a wide range of physiological processes in mammals such as reproduction, cardiovascular health, bone integrity, cognition and behavior. Besides its roles in human physiology, E2 is also involved in the development of many diseases, including various types of cancers. The mechanism proposed for explain the chemoprotective activity of naringenin suggests that the flavanone binds to ER $\alpha$ (estrogen receptor $\alpha$ ) as an antagonist, thereby limiting the effect of E2 in promoting cellular proliferation (Bulzomi et al., 2010).

\subsection{Cardiovascular effects}

Cardiovascular diseases (CVD) affect the heart and surrounding blood vessels and can take many forms, such as high blood pressure, coronary artery disease, heart disease and stroke. CVD is the largest cause of mortality in the EU and account for approximately $40 \%$ of deaths ( 2 million deaths per year). Chronic oxidative stress and inflammation are among the major factors causing CVD and its control by antioxidants including polyphenols is of great biological significance.

\subsubsection{Vasorelaxant and vasoprotective effects}

The vascular endothelial cells are very important in normal coronary functions. The regulation of vascular tone and blood flow to organs is controlled by endothelial cells, which synthesize and release a number of factors such as prostacyclin, nitric oxide (NO), endothelium-derived hyperpolarizing factor (EDHF) and endothelin. Among these factors, NO is critical in the preservation of normal vascular functions, and there is a clear relationship between coronary artery disease and NO dysfunctioning (Benavente-García and Castillo, 2008).

Flavonoids promote endothelial NO synthase (eNOS) and at the same time inhibit the inducible NOS (iNOS) (Olszanecki et al., 2002). In vitro, inhibition of iNOS in LPS-activated RAW 264.7 cells is not significant with flavanones (naringenin) in comparison to flavones and flavonols (apigenin, luteolin, quercetin), which may demonstrate the significance of a C2-C3 double bond (Kim et al., 1999). Recently, the vasorelaxant potential of hesperetin and hesperidin (Orallo et al., 2004) as well as naringenin and naringin (Orallo et al., 2005) was demonstrated in rats. These vasorelaxant effects are probably due to the inhibition of different phosphodiesterase isoenzymes.

\subsubsection{Effect on atherosclerosis and coronary heart disease}

There is compelling evidence that coronary heart disease (CHD) is principally related to an elevation of low-density lipoprotein (LDL) cholesterol. Cholesterol, cholesterol esters and triglycerides are transported within LDL particles (protein component ApoB) from their sites of absorption or synthesis to sites of bioactivity. In the artery wall, LDL oxidation and accumulation in macrophages (differentiated from circulating monocytes after adhesion to the 


\section{Journal of Food Composition and Analysis (2014),vol 33, p 85-104, DOI: 10.1016/j.jfca.2013.11.004}

\section{Journal homepage: www.elsevier.com/locate/jfca}

vessel wall) are early events of plaque formation (atherosclerosis). Atherosclerosis causes the hardening and narrowing of arteries, thus putting blood flow at risk. It is the usual cause of heart disease, stroke, and peripheral vascular disease.

The anti-atherosclerosis potential of citrus flavanones, hesperetin and naringenin, was attributed to their ability to regulate ApoB secretion and cellular cholesterol homeostasis in human hepatoma cells line HepG2. A decrease in ApoB accumulation was observed in the media following 24-h incubation with hesperetin and naringenin. This reduced ApoB secretion was related to a reduced cellular concentration of cholesteryl ester (Wilcox et al., 2001). The mechanism involved in naringenin anti-atherosclerosis activity was a reduced ApoB secretion primarily due to the inhibition of microsomal triglyceride transfer protein and the enhancement of LDL receptor (LDLr)-mediated ApoB-containing lipoprotein uptake (Borradaile et al., 2003).

Hesperetin was also shown to limit the rise of hepatic lipid contents and enzymes activities involved in triacylglycerol synthesis in rats fed with $1 \%$ orotic acid (Cha et al., 2001). Moreover, a hypolipidemic effect of hesperetin was also reported even during the high lipid concentrations (Kim et al., 2003).

In rats fed a high-cholesterol diet, $0.1 \%$ naringenin reduced the levels of plasma cholesterol and hepatic triacylglycerols. This effect was accompanied by a decrease in the activity of 3-hydroxy-3methylglutaryl-coenzyme A reductase and acyl-CoA cholesterol acyltransferase (Lee et al., 1999, 2003). In another study on rabbits fed with cholesterol-rich diet, naringin caused an increase in superoxide dismutase and catalase activities, thereby contributing to fighting oxidative stress. Moreover, naringin was also shown to up-regulate gene expression of superoxide dismutase, catalase and glutathione peroxidase (Jeon et al., 2001). More recently, naringin, the major grapefruit flavonoid, was studied for its anti-atherosclerosis effect in diet-induced hypercholesterolemia in mice (Chanet et al., 2012a). The study proved that naringenin supplementation at a nutritionally relevant level can reduce atherosclerosis in mice fed with high fat-high cholesterol diet. This protective effect could be related to improved dyslipidemia and biomarkers of endothelial dysfunction, but also to changes in gene expression that may lead to preservation of the vascular wall, as shown by the aorta transcriptomic analysis. The authors have also published a review that outlines the role of citrus flavanones in the protection of cardiovascular disease (Chanet et al., 2012b).

\subsection{Other biological effects}

Some examples of other interesting bioactivities of citrus flavanone are listed below:

- The antiviral activity of hesperidin has been demonstrated against herpes simples, polio, parainfluenza, and syncytial viral infections, while naringin was inactive (Kaul et al., 1985). In a recent study, hesperetin showed a moderate antimicrobial activity against Salmonella typhi and Salmonella typhimurium (Kawaguchi et al., 2004).

- A study by Matsuda et al. (1991) suggested that hesperidin has an antiallergic activity via the inhibition of histamine release from pertinent mast cells in rats.

- Oral administration of hesperidin caused a decrease in disease activity index, myeloperoxidase (MPO) activity and malondialdehyde (MDA) content in the dextran sulfate sodium (DSS)induced ulcerative colitis in mice (Xu et al., 2009).

- Knekt et al. (2002) found an association between a high intake of hesperetin and naringenin and a lower incidence of cerebrovascular disease and asthma. The findings support the clinical importance of monoamine oxidase (MAO-A and $\mathrm{B}$ ) inhibitors in the treatment of several neurological and psychiatric disorders.
Among the several flavonoids (flavones, thioflavones, flavanones) tested, the most active were the flavanones with highest selective inhibitory activity against MAO-B (Chimenti et al., 2010).

- Beneficial effects of naringenin on cis-platin-induced nephrotoxicity (Badarya et al., 2005) were reported.

\section{Conclusion}

In the past two to three decades there has been a growing awareness of the role of diet in the etiology of chronic diseases, notably cardiovascular disease (CVD) and some cancers that are major contributors to morbidity and mortality in industrialized countries such as Canada, Australia, the USA and European countries. A wide range of bioactive substances, including polyphenols has already been identified in food and beverages, and it is likely that many more exist. Citrus fruits and juices have long been considered a valuable part of a healthy and nutritious diet, and it is generally assumed that some of the micronutrients in citrus promote health and provide protection against chronic diseases. These micronutrients include mainly the simple flavanones hesperetin, naringenin, eriodictyol and isosakuranetin, but also more complex compounds like calyxin. In-depth knowledge of the composition of all citrus products has yet to be achieved. However, it can be concluded that chemists and nutritionists are progressing more and more rapidly. Various innovative and environmentally friendly techniques are being employed to extract flavanones from a wide range of plant sources. Moreover, analytical methods are improving in their efficiency, sensitivity in detecting minute quantities of complex flavanones, simultaneous quantification of a larger range of compounds, and reduction of analysis time.

Extensive studies have been carried out on the bioactivity of flavanone aglycones and their glycosides. However, a crucial missing link is the validation of the proposed mechanisms with the actual circulating flavanone metabolites. Interestingly, a very recent investigation showed that, unlike A-ring conjugates (hesperetin-7-glucuronide and naringenin-7-glucuronide), B-ring conjugates hesperetin-3'-sulfate, hesperetin-3'-glucuronide and naringenin- $4^{\prime}$-glucuronide in low concentrations $\left(2 \mu \mathrm{mol} \mathrm{L}^{-1}\right)$ were as potent as the corresponding aglycones in attenuating monocyte adhesion to TNF- $\alpha$-activated human umbilical vein endothelial cells (HUVEC) by affecting the expression of related genes (Chanet et al., 2013). This work provides a potential explanation for the vasculoprotective effects of flavanones.

In conclusion, it is now increasingly accepted that phytochemicals found in citrus and other plants consumed in the human diet can be helpful to reduce the risk of many chronic diseases. In our diet, citrus consumption has a considerable potential to expand as part of the overall recommended increase in fruit and vegetable consumption. There is a well-known saying:

"An apple a day keeps the doctor away."

After this survey of the literature, we would like to place emphasis on the recommendations of the French Nutrition \& Health Program (PNNS) and claim:

"Five fruits and vegetables a day keep chronic diseases away."

\section{References}

Abad-Garcia, B., Garmon-Lobato, S., Berrueta, L.A., Gallon, B., Vicente, F., 2012 Online characterization of 58 phenolic compounds in Citrus fruit juices from Spanish cultivars by high-performance liquid chromatography with photodiode-array detection coupled to electrospray ionization triple quadrupole mass spectrometry. Talanta 99, 213-224.

Agullo, G., Garnet-Payrastre, L., Femandez, Y., Anciaux, N., Demigné, C., Rémésy, C., 1996. Comparative effects of flavonoids on the growth, viability and metabolism of a colonic adenocarcinoma cell line (HT29 cells). Cancer Letters 105, 61-70. 


\section{Version définitive du manuscrit publiée dans / Final version of the manuscript published in : \\ Journal of Food Composition and Analysis (2014), vol 33, p 85-104, DOI: 10.1016/i.jfca.2013.11.004 \\ Journal homepage: www.elsevier.com/locate/jfca}

Ak, T., Gülçin, I., 2008. Antioxidant and radical scavenging properties of curcumin. Chemico-Biological Interactions 174, 27-37.

Allaf, T., Tomao, V., Ruiz, K., Chemat, F., 2013. Instant controlled pressure drop technology and ultrasound assisted extraction for sequential extraction of essential oil and antioxidants. Ultrasonics Sonochemistry 20, 239-246.

Al-Maharik, N., Botting, N.P., 2006. A facile synthesis of isoflavone 7-O-glucuronides. Tetrahedron Letters 47, 8703-8706.

Alu'datt, M.H., Rababah, T., Ereifej, K., Alli, I., 2013. Distribution, antioxidant and characterisation of phenolic compounds in soybeans, flaxseed and olives. Food Chemistry 139, 93-99.

Amaro, I.M., Rocha, J., Vila-Real, H., Eduardo-Figueira, M., Mota-Filipe, H., Sepodes, B., Ribeiro, M.H., 2009. Anti-inflammatory activity of naringin and the biosynthesised naringenin by naringinase immobilized in microstructured materials in a model of DSS-induced colitis in mice. Food Research International 42, 1010-1017.

Ames, B.N., Gold, L.S., 1998. The causes and prevention of cancer: the role of environment. Biotherapy 11, 205-220.

Anagnostopoulou, M.A., Kefalas, P., Papageorgiou, V.P., Assimopoulou, A.N., Boskou, D., 2006. Radical scavenging activity of various extracts and fractions of sweet orange peel (Citrus sinensis). Food Chemistry 94, 19-25.

Andújar, S.A., Filippa, M.A., Ferretti, F.H., Blanco, S.E., 2003. Isomerization of $4{ }^{\prime}$ methoxy-flavanone in alkaline medium. Determination of the enolate formation constant. Journal of Molecular Structure 636, 157-166.

Aranganathan, S., Panneer-Selvam, J., Sangeetha, N., Nalini, N., 2009. Modulatory efficacy of hesperetin (citrus flavanone) on xenobiotic-metabolizing enzymes during 1,2-dimethylhydrazine-induced colon carcinogenesis. Chemico-Biological Interactions 180, 254-261.

Asikin, Y., Taira, I., Inafuku-Teramoto, S., Sumi, H., Ohta, H., Takara, K., Wada, K., 2012. The composition of volatile aroma components, flavanones, and polymethoxylated flavones in shiikuwasha (Citrus depressa Hayata) peels of different cultivation lines. Journal of Agricultural and Food Chemistry 60, 7973-7980.

Badarya, O.A., Abdel-Maksoud, S., Ahmed, W.A., Owieda, G.H., 2005. Naringenin attenuates cisplatin nephrotoxicity in rats. Life Science 76, 2125-2135.

Banerjee, A., Basu, K., Sengupta, P.K., 2008. Interaction of 7-hydroxyflavone with human serum albumin: a spectroscopic study. Journal of Photochemistry and Photobiology 90, 33-40.

Barreca, D., Bellocco, E., Caristi, C., Leuzzi, U., Gattuso, G., 2011. Flavonoid profile and radical-scavenging activity of Mediterranean sweet lemon (Citrus limetta Risso) juice. Food Chemistry 129, 417-422.

Bartnick, D.D., Mohler, C.M., Houlihan, M., 2006. Methods for the production of food grade extracts. U.S. Patent Application, 20060088627.

Benavente-García, O., Castillo, J., 2008. Update on uses and properties of citrus flavonoids: new findings in anticancer, cardiovascular, and anti-inflammatory activity. Journal of Agricultural and Food Chemistry 56, 6185-6205.

Biesaga, M., Ochnik, U., Pyrzynska, K., 2009. Fast analysis of prominent flavonoids in tomato using a monolithic column and isocratic HPLC. Journal of Separation Science 32, 2835-2840.

Bimakr, M., Rahman, R.A., Taipa, F.S., Ganjloob, A., Salleha, L.M., Selamat, J., Hamid, A., Zaidul, I.S.M., 2011. Comparison of different extraction methods for the extraction of major bioactive flavonoid compounds from spearmint (Mentha spicata L.) leaves. Food and Bioproducts Processing 89, 67-72.

Bocco, A., Cuvelier, M.E., Richard, H., Berset, C., 1998. Antioxidant activity and phenolic composition of citrus peel and seed extracts. Journal of Agricultural and Food Chemistry 46, 2123-2129.

Bodet, C., La, V.D., Epifano, F., Grenier, D., 2008. Naringenin has anti-inflammatory properties in macrophage and ex vivo human whole-blood models. Journal of Periodontal Research 43, 400-407.

Bohm, B.A., 1994. The minor flavonoids. In: Harborne, J.B. (Ed.), The Flavonoids: Advances in Research Since 1986. Chapman \& Hall, London, UK, pp. 387-440.

Boonkird, S., Phisalaphong, C., Phisalaphong, M., 2008. Ultrasound-assisted extraction of capsaicinoids from Capsicum frutescens on a lab- and pilot-plant scale. Ultrasonic Sonochemistry 15, 1075-1079.

Boros, B., Jakabovaa, S., Dornyeia, A., Horvathd, G., Pluhare, Z., Kilar, F., Felingera, A., 2010. Determination of polyphenolic compounds by liquid chromatographymass spectrometry in Thymus species. Journal of Chromatography A 1217, 7972-7980.

Borradaile, N.M., De Dreu, L.E., Huff, M.W., 2003. Inhibition of net HepG2 cell apolipoprotein B secretion by the citrus flavonoid naringenin involves activation of phosphatidylinositol 3-kinase, independent of insulin receptor substrate-1 phosphorylation. Diabetes 52, 2554-2561.

Bouayed, J., Deußer, H., Hoffmann, L., Bohn, T., 2012. Bioaccessible and dialysable polyphenols in selected apple varieties following in vitro digestion vs. their native patterns. Food Chemistry 131, 1466-1472

Bouktaib, M., Atmanib, A., Rolando, C., 2002. Regio- and stereo-selective synthesis of the major metabolite of quercetin, quercetin-3-O- $\beta$-D-glucuronide. Tetrahedron Letters 43, 6263-6266.

Boumendjel, A., Blanc, M., Williamson, G., Barron, D., 2009. Efficient synthesis of flavanone glucuronides. Journal of Agricultural and Food Chemistry 57, 7264-7267.

Brand, W., Van der Wel, P.A.I., Rein, M.J., Barron, D., Williamson, G., van Bladeren P.J., Rietjens, I.M.C.M., 2008. Metabolism and transport of the citrus flavonoid hesperetin in Caco-2 cell monolayers. Drug Metabolism and Disposition 36, 1794-1802.

Brand, W., Shao, J., Hoek-vanden Hil, E.F., Van Elk, K.N., Spenkelink, B., Haan, L.H.J.D., Rein, M.J., Dionisi, F., Williamson, G., Van Bladeren, P.J., Rietjens, I.M.C.M., 2010.
Stereoselective conjugation, transport and bioactivity of $S$ - and $R$-hesperetin enantiomers in vitro. Journal of Agricultural and Food Chemistry 58, 6119-6125.

Brett, G.M., Hollands, W., Needs, P.W., Teucher, B., Dainty, J.R., Davis, B.D., Brodbelt, J.S., Kroon, P.A., 2009. Absorption, metabolism and excretion of flavanones from single portions of orange fruit and juice and effects of anthropometric variables and contraceptive pill use on flavanone excretion. British Journal of Nutrition 101, 664-675

Brown, G.C., Borutaite, V., 2006. Interactions between nitric oxide, oxygen, reactive oxygen species and reactive nitrogen species. Biochemical Society Transactions 34, 953-956.

Bulzomi, P., Bolli, A., Galluzzo, P., Leone, S., Acconcia, F., Marino, M., 2010. Naringenin and $17 \beta$-estradiol coadministration prevents hormone-induced human cancer cell growth. IUBMB Life 62, 51-60.

Cai, Y., Mei, S., Jie, X., Luo, Q., Corke, H., 2006. Structure-radical scavenging activity relationships of phenolic compounds from traditional Chinese medicinal plants. Life Science 78, 2872-2888.

Calvarano, M., Postorino, E., Gionfriddo Calvarano, I., Bovalo, F., 1996. Naringin extraction from exhausted bergamot peels. Perfumer Flavorist 21, 1-4.

Cano, A., Medina, A., Bermejo, A., 2008. Bioactive compounds in different citrus varieties. Discrimination among cultivars. Journal of Food Composition and Analysis 21, 377-381.

Cao, H., Chen, X., Sun, H., Tetsuro, S., Zhou, J., Sun, W., Lv, H., Wang, X., 2010. Pharmacokinetics-based elucidation on disparity in clinical effectiveness between varieties of Zhi Zhu Wan, a Traditional Chinese Medical formula. Journal of Ethnopharmacology 128, 606-610.

Casagrande, F., Darbon, J.M., 2001. Effects of structurally related flavonoids on cell cycle progression of human melanoma cells: regulation of cyclin-dependent kinases CDK2 and CDK1. Biochemical Pharmacology 61, 1205-1215.

Cha, J.Y., Cho, Y.S., Kim, I., Anno, T., Rahman, S.M., Yanagita, T., 2001. Effect of hesperetin, a citrus flavonoid, on the liver triacylglycerol content and phosphatidate phosphohydrolase activity in orotic acid-fed rats. Plant Foods for Human Nutrition 56, 349-358.

Chandrasekhar, S., Vijeender, K., Venkatram-Reddy, K., 2005. New synthesis of flavanones catalyzed by L-proline. Tetrahedron Letters 46, 6991-6993.

Chanet, A., Milenkovic, D., Deval, C., Potier, M., Constans, J., Mazur, A., BennetauPelissero, C., Morand, C., Bérard, A.M., 2012a. Naringin, the major grapefruit flavonoid, specifically affects atherosclerosis development in diet-induced hypercholesterolemia in mice. Journal of Nutritional Biochemistry 23, 469-477.

Chanet, A., Milenkovic, D., Manach, C., Mazur, A., Morand, C., 2012b. Citrus flavanones: what is their role in cardiovascular protection? Journal of Agricultural and Food Chemistry 60, 8809-8822.

Chanet, A., Milenkovic, D., Claude, S., Maier, J.A.M., Khan, M.K., Rakotomanomana, N., Shinkaruk, S., Berard, A.M., Bennetau-Pelissero, C., Mazur, A., Morand, C., 2013. Flavanone metabolites decrease monocyte adhesion to TNF-a-activated endothelial cells by modulating expression of atherosclerosis-related genes. British Journal of Nutrition 110, 587-598.

Chebrolua, K.K., Jayaprakashaa, G.K., Jifon, J., Patil, B.S., 2011. Optimization of flavanones extraction by modulating differential solvent densities and centrifuge temperatures. Talanta 85, 353-362.

Cheigh, C.I., Chung, E.Y., Chung, M.S., 2012. Enhanced extraction of flavanones hesperidin and narirutin from Citrus unshiu peel using subcritical water. Journal of Food Engineering 110, 472-477.

Chemat, F., Tomao, V., Virot, M., 2008. Ultrasound-assisted extraction in food analysis. In: Ötles, S. (Ed.), Handbook of Food Analysis Instruments. CRC Press, Boca Raton, FL, USA, pp. 85-103.

Chemat, F., Abert-Vian, M., Zill-e-Huma, 2009. Microwave assisted - separations: green chemistry in action. In: Pearlman, J.T. (Ed.), Green Chemistry Research Trends. Nova Science Publishers Inc., United States, pp. 1-30.

Cheynier, V., 2005. Polyphenols in foods are more complex than often thought. American Journal of Clinical Nutrition 81, 223S-229S.

Chimenti, F., Fioravanti, R., Bolasco, A., Chimenti, P., Secci, D., Rossi, F., Yáñez, M., Orallo, F., Ortuso, F., Alcaro, S., Cirilli, R., Ferretti, R., Sanna, M.L., 2010. A new series of flavones, thioflavones, and flavanones as selective monoamine oxidase-B inhibitors. Bioorganic and Medicinal Chemistry 18, 1273-1279.

Choudhury, R., Chowrimootoo, G., Srai, K., Debnam, E., Rice-Evans, C.A., 1999 Interaction of the flavonoid naringenin in the gastrointestinal tract and the influence of glycosylation. Biochemical and Biophysical Research Communications 265, 410-415.

Climent, M.J., Corma, A., Iborra, S., Primo, J., 1995. Base catalysis for fine chemicals production: Claisen-Schmidt condensation on zeolites and hydrotalcites for the production of chalcones and flavanones of pharmaceutical interest. Journal of Catalysis 151, 60-66.

Cooper-driver, G., Bhattacharya, M., 1998. Role of phenolics in plant evolution. Phytochemistry 49, 1165-1174.

Cortes-Concepcion, J.A., Patcas, F., Amiridis, M.D., 2010. Effect of Li on the catalytic activity of $\mathrm{MgO}$ for the synthesis of flavanone. Applied Catalysis A-General 386, $1-8$

Curto, R.L., Tripodo, M.M., Leuzzi, U., Giuffrè, D., Vaccarino, C., 1992. Flavonoids recovery and SCP production from orange peel. Bioresource Technology 42, 83-87.

Del Rio, D., Costa, L., Lean, M., Crozier, A., 2010. Polyphenols and health: what compounds are involved? Nutrition, Metabolism and Cardiovascular Diseases 20, 1-6.

Dhuique-Mayer, C., Caris-Veyrat, C., Ollitrault, P., Curk, F., Amiot, M.J., 2005. Varietal and interspecific influence on micronutrient contents in citrus from the Mediterranean area. Journal of Agricultural and Food Chemistry 53, 2140-2145. 


\section{Version définitive du manuscrit publiée dans / Final version of the manuscript published in : \\ Journal of Food Composition and Analysis (2014),vol 33, p 85-104, DOI: 10.1016/j.jfca.2013.11.004 Journal homepage: www.elsevier.com/locate/jfca}

Di Donna, L., Taverna, D., Mazzotti, F., Benabdelkamel, H., Attya, M., Napoli, A., Sindona, G., 2013. Comprehensive assay of flavanones in citrus juices and beverages by UHPLC-ESI-MS/MS and derivatization chemistry. Food Chemistry 141, 2328-2333.

Di Lecce, G., Martínez-Huélamo, M., Tulipani, S., Vallverdú-Queralt, A., LamuelaRaventós, R.M., 2013. Setup of a UHPLC-QqQ-MS method for the analysis of phenolic compounds in cherry tomatoes, tomato sauce, and tomato juice. Journal of Agricultural and Food Chemistry 61, 8373-8380.

Di Majo, D., Giammanco, M., Guardia, M., Tripoli, E., Giammanco, S., Finotti, E., 2005. Flavanones in citrus fruits: structure-antioxidant activity relationships. Food Research International 38, 1161-1166.

Dufour, C., Dangles, O., 2005. Flavonoid-serum albumin complexation: determination of binding constants and binding sites by fluorescence spectroscopy. Biochimica Biophysica Acta - General Subjects 1721, 164-173.

Dykes, L., Rooney, W.L., Rooney, L.W., 2013. Evaluation of phenolics and antioxidant activity of black sorghum hybrids. Journal of Cereal Science 58, 278-283.

Emim, J.A., Oliveira, A.B., Lapa, A.J., 1994. Pharmacological evaluation of the antiinflammatory activity of a citrus bioflavonoid, hesperidin, and the isoflavonoids, duartin and claussequinone, in rats and mice. Journal of Pharmacy and Pharmacology 46, 118-122.

Erlund, I., 2004. Review of the flavonoids quercetin, hesperetin, and naringenin. Dietary sources, bioactivities, bioavailability, and epidemiology. Nutritional Research 24, 851-874.

Erlund, I., Meririnne, E., Alfthan, G., Aro, A., 2001. Plasma kinetics and urinary excretion of the flavanones naringenin and hesperetin in humans after ingestion of orange juice and grapefruit juice. Journal of Nutrition 131, 235-241.

Esaki, S., Nishiyama, K., Sugiyama, N., Nakajima, R., Takao, Y., Kamiya, S., 1994. Preparation and taste of certain glycosides of flavanones and of dihydrochalcones. Bioscience, Biotechnology, and Biochemistry 58, 1479-1485.

Escudero-López, B., Cerrillo, I., Herrero-Martín, G., Hornero-Méndez, D., GilIzquierdo, A., Medina, S., Ferreres, F., Berná, G., Martín, F., Fernández-Pachón, M.S., 2013. Fermented orange juice: source of higher carotenoid and flavanone contents. Journal of Agricultural and Food Chemistry 61, 8773-8782.

Felgines, C., Texier, O., Morand, C., Manach, C., Scalbert, A., Regerat, F., Remesy, C., 2000. Bioavailability of the flavanone naringenin and its glycosides in rats. American Journal of Physiology: Gastrointestinal and Liver Physiology 279, G1148-G1154.

Finotti, E., Di Majo, D., 2003. Influence of solvents on the antioxidant property of flavonoids. Nahrung 47, 186-187.

Forman, H., Fukuto, J., Miller, T., Zhang, H., Rinna, A., Levy, S., 2008. The chemistry of cell signaling by reactive oxygen and nitrogen species and 4-hydroxynonenal. Archives of Biochemistry and Biophysics 477, 183-195.

Fowler, Z.L., Koffas, M.A.G., 2009. Biosynthesis and biotechnological production of flavanones: current state and perspectives. Applied Microbiology and Biotechnology 83, 799-808.

Fox, D.W., Savage, W.L., Wender, S.H., 1953. Hydrolysis of some flavonoid rhamnoglucosides to flavonoid glucosides. Journal of the American Chemical Society 75, 2504-2505.

French, D., Schifano, P., Cortés-Concepción, J., Hargrove-Leak, S., 2010. Li-Al layered double hydroxides as catalysts for the synthesis of flavanone. Catalysis Communications 12, 92-94.

Frydoonfar, H.R., McGrath, D.R., Spigelman, A.D., 2003. The variable effect on proliferation of a colon cancer cell line by the citrus fruit flavonoid naringenin. Colorectal Disease 5, 149-152.

Fumeaux, R., Menozzi-Smarrito, C., Stalmach, A., Munari, C., Kraehenbuehl, K., Steiling, H., Crozier, A., Williamson, G., Barron, D., 2010. First synthesis, characterization, and evidence for the presence of hydroxycinnamic acid sulfate and glucuronide conjugates in human biological fluids as a result of coffee consumption. Organic and Biomolecular Chemistry 8, 5199-5211.

Galati, E.M., Monforte, M.T., Kirjavainen, S., Forestieri, A.M., Trovato, A., Tripodo, M.M., 1994. Biological effects of hesperidin, a citrus flavonoid. (Note I): antiinflammatory and analgesic activity. Farmaco 40, 709-712.

Galland, S., Rakotomanomana, N., Dufour, C., Mora, N., Dangles, O., 2008. Synthesis of hydroxycinnamic acid glucuronides and investigation of their affinity for human serum albumin. Organic and Biomolecular Chemistry 6, 4253-4260.

Gao, K., Henning, S., Niu, Y., Youssefian, A.A., Seeram, N.P., Xu, A., Heber, D., 2006. The citrus flavonoid naringenin stimulates DNA repair in prostate cancer cells. Journal of Nutritional Biochemistry 17, 89-95.

Gardana, C., Guarnieri, S., Riso, P., Simonetti, P., Porrini, M., 2007. Flavanone plasma pharmacokinetics from blood orange juice in human subjects. British Journal of Nutrition 98, 165-172.

Gattuso, G., Barreca, D., Gargiulli, C., Leuzzi, U., Caristi, C., 2007. Flavonoid composition of citrus juices. Molecules 12, 1641-1673.

Ghuman, J., Zunszain, P.A., Petitpas, I., Bhattacharya, A.A., Otagiri, M., Curry, S., 2005. Structural basis of the drug-binding specificity of human serum albumin. Journal of Molecular Biology 353, 38-52.

Giannuzzo, A.N., Boggetti, H.J., Nazareno, M.A., Mishima, H.T., 2003. Supercritical fluid extraction of naringin from the peel of Citrus paradise. Phytochemical Analysis 14, 221-223.

Gil-Izquierdo, A., Gil, M.I., Tomas-Barberan, F.A., Ferreres, F., 2003. Influence of industrial processing on orange juice flavanone solubility and transformation to chalcones under gastrointestinal conditions. Journal of Agricultural and Food Chemistry 51, 3024-3028.

Gimenez-Bastida, J., Martinez-Florensa, M., Espin, J.C., Tomas-Barberan, F.A., Garcia-Conesa, M.T., 2009. A citrus extract containing flavanones represses plasminogen activator inhibitor-1 (PAI-1) expression and regulates multiple inflammatory, tissue repair, and fibrosis genes in human colon fibroblasts. Journal of Agricultural and Food Chemistry 57, 9305-9315.

González, E.A., Nazareno, M.A., Borsarelli, C.D., 2002. Enthalpy-entropy compensation effect in the chalcone formation from naringin in water-ethanol mixtures. Journal of Chemical Society Perkin Transactions 2 2052-2056.

González-Manzano, S., González-Paramás, A., Santos-Buelga, C., Duenãs, M., 2009. Preparation and characterization of catechin sulfates, glucuronides, and methylethers with metabolic interest. Journal of Agricultural and Food Chemistry 57, 1231-1238.

González-Molina1, E., Domínguez-Perles, R., Moreno, D.A., García-Viguer, C., 2010. Natural bioactive compounds of Citrus limon for food and health. Journal of Pharmaceutical and Biomedical Analysis 51, 327-345.

Goulas, V., Manganaris, G.A., 2012. Exploring the phytochemical content and the antioxidant potential of Citrus fruits grown in Cyprus. Food Chemistry 131, 39-47.

Hanessian, S., Kothakonda, K.K., 2005. Natural products as scaffolds for chemical diversification: solution-phase parallel synthesis of a series of naringin analogues. Journal of Combinatorial Chemistry 7, 837-842.

Harnly, J.M., Doherty, R.F., Beecher, G.R., Holden, J.M., Haytowitz, D.B., Bhagwat, S., Gebhardt, S., 2006. Flavonoid content of U.S. fruits, vegetables, and nuts. Journal of Agricultural and Food Chemistry 54, 9966-9977.

Hayat, K., Hussain, S., Abbas, S., Farooq, U., Ding, B., Xia, S., Jia, C., Zhang, X., Xia, W., 2009. Optimized microwave-assisted extraction of phenolic acids from citrus mandarin peels and evaluation of antioxidant activity in vitro. Separation and Purification Technology 70, 63-70.

Hayat, K., Zhang, X., Chen, H., Xia, S., Jia, C., Zhong, F., 2010a. Liberation and separation of phenolic compounds from citrus mandarin peels by microwave heating and its effect on antioxidant activity. Separation and Purification Technology 73, 371-376.

Hayat, K., Zhang, X., Farooq, U., Abbas, S., Xia, S., Jia, C., Zhong, F., Zhang, J., 2010b. Effect of microwave treatment on phenolic content and antioxidant activity of citrus mandarin pomace. Food Chemistry 123, 423-429.

He, X.M., Carter, D.C., 1992. Atomic structure and chemistry of human serum albumin. Nature 358, 209-215.

Hsieh, H.K., Lee, T.H., Wang, J.P., Wang, J.J., Lin, C.N., 1998. Synthesis and antiinflammatory effect of chalcones and related compounds. Pharmaceutical Research 15, 39-46.

Hu, Y.J., Wang, Y., Ou-Yang, Y., Zhou, J., Liu, Y., 2010. Characterize the interaction between naringenin and bovine serum albumin using spectroscopic approach. Journal of Luminescence 130, 1394-1399.

Igual, M., Garcia-Martinez, E., Camacho, M.M., Martinez-Navarrete, N., 2013. Jam processing and storage effects on $\beta$-carotene and flavonoids content in grapefruit. Journal of Functional Foods 5, 736-737, 44.

Iijima, Y., Suda, K., Suzuki, T., Aoki, K., Shibata, D., 2008. Metabolite profiling of chalcones and flavanones in tomato fruit. Journal of Japanese Society of Horticulture Science 77, 94-102.

Iwashina, T., 2000. The structure and distribution of the flavonoids in plants. Journal of Plant Research 113, 287-299.

Jeon, S.M., Bok, S.H., Jang, M.K., Lee, M.K., Nam, K.T., Park, Y.B., Rhee, S.J., Choi, M.S., 2001. Antioxidative activity of naringin and lovastatin in high cholesterol-fed rabbits. Life Science 69, 2855-2866.

Jeong, S.M., Kim, S.Y., Kim, D.R., Jo, S.C., Nam, K.C., Ahn, D.U., Lee, S.C., 2004. Effect of heat treatment on the antioxidant activity of extracts from citrus peels. Journal of Agricultural and Food Chemistry 52, 3389-3393.

Jez, J.M., Noel, J.P., 2002a. Reaction mechanism of chalcone isomerase: pH dependence, diffusion control, and product binding differences. Journal of Biological Chemistry 277, 1361-1369.

Jez, J.M., Bowman, M.E., Noel, J.P., 2002b. Role of hydrogen bonds in the reaction mechanism of chalcone isomerase. Biochemistry 41, 5168-5176.

Kanaze, F.I., Bounartzi, M.I., Georgarakis, M., Niopas, I., 2007. Pharmacokinetics of the citrus flavanone aglycones hesperetin and naringenin after single oral administration in human subjects. European Journal of Clinical Nutrition 61, $472-477$.

Kanno, S., Shouji, A., Asou, K., Ishikawa, M., 2003. Effects of naringin on hydrogen peroxide-induced cytotoxicity and apoptosis in P388 cells. Journal of Pharmacological Science 92, 166-170.

Kaul, T.N., Middleton, E., Ogra, P.L., 1985. Antiviral effect of flavonoids on human viruses. Journal of Medical Virology 15, 71-79.

Kawaguchi, K., Kikuchi, S., Hasunuma, R., Maruyama, H., Yoshikawa, T., Kumazawa, Y., 2004. A citrus flavonoid hesperidin suppresses infection-induced endotoxin shock in mice. Biological and Pharmaceutical Bulletin 27, 679-683.

Kawaii, S., Tomono, Y., Katase, E., Ogawa, K., Yano, M., 1999. Effect of citrus flavonoids on HL-60 cell differentiation. Anticancer Research 19, 1261-1269.

Keilig, K., Ludwig-Müller, J., 2009. Effect of flavonoids on heavy metal tolerance in Arabidopsis thaliana seedlings. Botanical Studies 50, 311-318.

Khan, M.K., Abert-Vian, M., Fabiano-Tixier, A.S., Dangles, O., Chemat, F., 2010a. Ultrasound-assisted extraction of polyphenols (flavanone glycosides) from orange (Citrus sinensis L.) peel. Food Chemistry 119, 851-858.

Khan, M.K., Rakotomanomana, N., Loonis, M., Dangles, O., 2010b. Chemical synthesis of flavanone glucuronides. Journal of Agricultural and Food Chemistry 58, 8437-8443.

Khan, M.K., Rakotomanomana, N., Dufour, C., Dangles, O., 2011. Binding of citrus flavanones and their glucuronides and chalcones to human serum albumin. Food and Function 2, 617-626. 


\section{Version définitive du manuscrit publiée dans / Final version of the manuscript published in : \\ Journal of Food Composition and Analysis (2014),vol 33, p 85-104, DOI: 10.1016/ị.jfca.2013.11.004 \\ Journal homepage: www.elsevier.com/locate/jfca}

Kim, H., Cheon, B.S., Kim, Y.H., Kim, S.Y., Kim, H.P., 1999. Effects of naturally occurring flavonoids on nitric oxide production in the macrophage cell line RAW 264.7 and their structure-activity relationships. Biochemical Pharmacology 58, 759-765

Kim, H., Jeong, T.S., Lee, M.K., Park, Y.B., Choi, M.S., 2003. Lipid-lowering efficacy of hesperetin metabolites in high-cholesterol fed rats. Clinica Chimica Acta 327, 129-137.

Kim, M.R., Kim, W.C., Lee, D.Y., Kim, C.W., 2007a. Recovery of narirutin by adsorption on a non-ionic polar resin from a water-extract of Citrus unshiu peels. Journal of Food Engineering 78, 27-32.

Kim, J.B., Han, A., Park, E., Kim, J.Y., Cho, W., Lee, J., Seo, E.K., Lee, K.T., 2007b. Inhibition of LPS-induced iNOS, COX-2 and cytokines expression by poncirin through the NF- $\kappa$ B inactivation in RAW 264.7 macrophage cells. Biological and Pharmaceutical Bulletin 30, 2345-2351.

Kim, J.W., Lee, B.C., Lee, J.H., Nam, K.C., Lee, S.C., 2008. Effect of electron-beam irradiation on the antioxidant activity of extracts from Citrus unshiu pomaces. Radiation Physics and Chemistry 77, 87-91.

Knekt, P., Kumpulainen, J., Järvinen, R., Rissanen, H., Heliövaara, M., Reunanen, A. Hakulinen, T., Aromaa, A., 2002. Flavonoid intake and risk of chronic diseases. American Journal of Clinical Nutrition 76, 560-568.

Kobayashi, S., Konishi, Y., 2008. Transepithelial transport of flavanone in intestinal Caco-2 cell monolayers. Biochemical and Biophysical Research Communications 368, 23-29.

Kobayashi, S., Tanabe, S., Sugiyama, M., Konishi, Y., 2008. Transepithelial transport of hesperetin and hesperidin in intestinal Caco-2 cell monolayers. Biochimica Biophysica Acta - Biomembranes 1778, 33-41.

Koca, U., Berhow, M.A., Febres, V.J., Champ, K.I., Carrillo-Mendoza, O., Moore, G.A. 2009. Decreasing unpalatable flavonoid components in the effect of transformation construct. Physiologia Plantarum 137, 101-114.

Kometani, T., Nishimura, T., Nakae, T., Takii, H., Okada, S., 1996. Synthesis of neohesperidin glycosides and naringin glycosides by cyclodextrin glucanotransferase from an Alkalophilic Bacillus species. Bioscience, Biotechnology, and Biochemistry 60, 645-649.

Kootstra, A., 1994. Protection from UV-B-induced DNA damage by flavonoids. Plant Molecular Biology 26, 771-774.

Kratz, F., 2008. Albumin as a drug carrier: design of prodrugs, drug conjugates and nanoparticles. Journal of Controlled Release 132, 171-183.

Krbechek, L., Inglett, G.E., Holik, M., Dowling, B., Wagner, R., Riter, R., 1968. Dihydrochalcones. Synthesis of potential sweetening agents. Journal of Agricultural and Food Chemistry 16, 108-112.

Kris-etherton, P.M., Hecker, K.D., Bonanome, A., Coval, S.M., Binkoski, A.E., Hilpert K.F., Griel, A.E., Etherton, T.D., 2002. Bioactive compounds in foods: their role in the prevention of cardiovascular disease and cancer. American Journal of Medicine 113, 71-88.

Lee, S., Park, Y.B., Bae, K.H., Bok, S.H., Kwon, Y.K., Lee, E.S., Choi, M.S., 1999 Cholesterol-lowering activity of naringenin via inhibition of 3-hydroxy3-methylglutaryl coenzyme a reductase and acyl coenzyme A: cholesterol acyltransferase in rats. Annals of Nutrition and Metabolism 43, 173-180.

Lee, M., Moon, S.S., Lee, S.E., Bok, S.H., Jeong, T.S., Park, Y.B., Choi, M.S., 2003. Naringenin 7-O-cetyl ether as inhibitor of HMG-CoA reductase and modulator of plasma and hepatic lipids in high cholesterol-fed rats. Bioorganic and Medicinal Chemistry 11, 393-398.

Lewinsohn, E., Britsch, L., Mazur, Y., Gresse, J., 1989. Flavanone glycoside biosynthesis in citrus. Plant Physiology 91, 1323-1328.

Li, B.B., Smith, B., Hossain, M.M., 2006a. Extraction of phenolics from citrus peels: II. Enzyme-assisted extraction method. Separation and Purification Technology 48, 189-196

Li, B.B., Smith, B., Hossain, M.M., 2006b. Extraction of phenolics from citrus peels: Solvent extraction method. Separation and Purification Technology 48, 182-188.

Li, W., Wang, Z., Wang, Y.P., Jiang, C., Liu, Q., Sun, Y.S., Zheng, Y.N., 2012. Pressurised liquid extraction combining LC-DAD-ESI/MS analysis as an alternative method to extract three major flavones in Citrus reticulata 'Chachi' (Guangchenpi). Food Chemistry 130, 1044-1049.

Liu, Y., Li, Y., Liu, S., Li, J., Yao, S., 2004. Monitoring the self-assembly of chitosan/ glutaraldehyde/cysteamine/Au-colloid and the binding of human serum albumin with hesperidin. Biomaterials 25, 5725-5733.

Lu, Z., Zhang, Y., Liu, H., Yuan, J., Zheng, Z., Zou, G., 2007. Transport of a cancer chemopreventive polyphenol, resveratrol: interaction with serum albumin and hemoglobin. Journal of Fluorescence 17, 580-587.

Luque-Garcia, J.L., Luque de Castro, M.D., 2003. Ultrasound: a powerful tool for leaching. Trends in Analytical Chemistry 22, 41-47.

Ma, Y., Ye, X., Hao, Y., Xu, G., Xu, G., Liu, D., 2008a. Ultrasound-assisted extraction of hesperidin from Penggan (Citrus reticulata) peel. Ultrasonics Sonochemistry 15 227-232.

Ma, Y., Ye, X., Fang, Z., Chen, J., Xu, G., Liu, D., 2008b. Phenolic compounds and antioxidant activity of extracts from ultrasonic treatment of Satsuma mandarin (Citrus unshiu Marc.) peels. Journal of Agricultural and Food Chemistry 56, 5682-5690.

Ma, Y., Chen, J., Liu, D., Ye, X., 2008c. Effect of ultrasonic treatment on the total phenolic and antioxidant activity of extracts from citrus peel. Journal of Food Science 73, 115-120

Ma, Y., Chen, J., Liu, D., Ye, X., 2009. Simultaneous extraction of phenolic compounds of citrus peel extracts: effect of ultrasound. Ultrasonics Sonochemistry $16,57-62$.

Manach, C., Morand, C., Gil-Izquierdo, A., Bouteloup-Demange, C., Rémésy, C., 2003. Bioavailability in humans of the flavanones hesperidin and narirutin after the ingestion of two doses of orange juice. European Journal of Clinical Nutrition 57, 235-242.

Manthey, J.A., Grohmann, K., 1996. Concentrations of hesperidin and other orange peel flavonoids in citrus processing byproducts. Journal of Agricultural and Food Chemistry 44, 811-814.

Manthey, J.A., Guthrie, N., 2002. Antiproliferative activities of citrus flavonoids against six human cancer cell lines. Journal of Agricultural and Food Chemistry 50, 5837-5843.

Manthey, J.A., Grohmann, K., Guthrie, N., 2001. Biological properties of citrus flavonoids pertaining to cancer and inflammation. Current Medicinal Chemistry 8, 135-153.

Marais, J.P.J., Deavours, B., Dixon, R.A., Ferreira, D., 2006. The stereochemistry of flavonoids. In: Grotewold, E. (Ed.), The Science of Flavonoids. Springer Science and Business Media Inc., USA, pp. 1-46.

Martens, S., Mithöfer, A., 2005. Flavones and flavone synthases. Phytochemistry 66, 2399-2407.

Mato, M., Onozaki, T., Ozeki, Y., Higeta, D., Itoh, Y., Yoshimoto, Y., Ikeda, H., Yoshida, H., Shibata, M., 2000. Flavonoid biosynthesis in white-flowered Sim carnations (Dianthus caryophyllus). Scientia Horticulturae 84, 333-347.

Matsuda, H., Yano, M., Kubo, M., Iinuma, M., Oyama, M., Mizuno, M., 1991. Pharmacological study on citrus fruits. II. Anti-allergic effect of fruit of Citrus unshiu MARKOVICH (2). On flavonoid components. Yakugaku Zasshi 111, $193-$ 198

Matsumoto, H., Ikoma, Y., Sugiura, M., Yano, M., Hasegawa, Y., 2004. Identification and quantification of the conjugated metabolites derived from orally administered hesperidin in rat plasma. Journal of Agricultural and Food Chemistry 52, 6653-6659.

Menichini, F., Houghton, P.J., Jones, P., Liu, B., Loizzo, M., Tundis, R., De Luca, D., De Cindio, B., Menichini, F., Perseud, S., 2009. In vitro antidiabetic activity effect of Citrus medica cv. diamante peel extract. Annuals in Nutrient Metabolism 55, 596

Miles, C.O., Main, L., 1985. Kinetics and mechanism of the cyclization of $2^{\prime}, 6^{\prime}-$ dihydroxy-4,4'-dimethoxychalcone; influence of the $6^{\prime}$-hydroxy group on the rate of cyclization under neutral conditions. Journal of Chemical Society Perkin Translation 2 1639-1642.

Miyake, Y., Shimoi, K., Kumazawa, S., Yamamoto, K., Kinae, N., Osawa, T., 2000. Identification and antioxidant activity of flavonoid metabolites in plasma and urine of eriocitrin-treated rats. Journal of Agricultural and Food Chemistry 48, 3217-3224.

Miyake, Y., Sakurai, C., Usuda, M., Fukumoto, S., Hiramitsu, M., Sakaida, K., Osawa, T., Kondo, K., 2006. Difference in plasma metabolite concentration after ingestion of lemon flavonoids and their aglycones in human. Journal of Nutritional Science and Vitaminology 52, 54-60.

Moon, J.H., Tsushida, T., Nakahara, K., Terao, J., 2001. Identification of quercetin 3-Obeta-D-glucuronide as an antioxidative metabolite in rat plasma after oral administration of quercetin. Free Radical Biology and Medicine 30, 1274-1285.

Moure, A., Cruz, J.M., Franco, D., Dominguez, J.M., Sineiro, J., Dominguez, H., Nunez, M.J., Parajo, J.C., 2001. Natural antioxidants from residual sources. Food Chemistry $72,145-171$

Mullen, W., Archeveque, M.A., Edwards, C.A., Matsumoto, H., Crozier, A., 2008. Bioavailability and metabolism of orange juice flavanones in humans: impact of a full-fat yogurt. Journal of Agricultural and Food Chemistry 56, 11157-11164.

Murota, K., Hotta, A., Ido, H., Kawai, Y., Moon, J.H., Sekido, K., Hayashi, H., Inakuma, T., Terao, J., 2007. Antioxidant activity of albumin-bound quercetin metabolites after onion consumption in humans. Journal of Medical Investigation 54, 370-374.

Needs, P.W., Kroon, P.A., 2006. Convenient syntheses of metabolically important quercetin glucuronides and sulfates. Tetrahedron 62, 6862-6868.

Nogata, Y., Sakamoto, K., Shiratsuchi, H., Ishii, T., Yano, M., Ohto, H., 2006. Flavonoid composition of fruit tissues of citrus species. Bioscience, Biotechnology, and Biochemistry 70, 178-192.

Olszanecki, R., Gebska, A., Kozlovski, V.I., Gryglewski, R.J., 2002. Flavonoids and nitric oxide synthase. Journal of Physiology and Pharmacology 53, 571-584.

Orallo, F., Alvarez, E., Basaran, H., Lugnier, C., 2004. Comparative study of the vasorelaxant activity, superoxide-scavenging ability and cyclic nucleotide phosphodiesterase-inhibitory effects of hesperetin and hesperidin. NaunynSchmiedeberg's Archives of Pharmacology 370, 452-463.

Orallo, F., Camiña, M., Alvarez, E., Basaran, H., Lugnier, C., 2005. Implication of cyclic nucleotide phosphodiesterase inhibition in the vasorelaxant activity of the citrus-fruits flavonoid (+/-)-naringenin. Planta Medica 71, 99-107.

Oravcová, J., Böhs, B., Lindner, W., 1996. Drug-protein binding studies new trends in analytical and experimental methodology. Journal of Chromatography B: Biomedical Sciences and Applications 677, 1-28.

Oufedjikh, H., Mahrouz, M., Amiot, M.J., Lacroix, M., 2000. Effect of $\gamma$-irradiation on phenolic compounds and phenylalanine ammonia-lyase activity during storage in relation to peel injury from peel of Citrus clementina Hort. ex. Tanaka. Journal of Agricultural and Food Chemistry 48, 559-565.

Oyama, K., Kondo, T., 2004. Total synthesis of apigenin 7,4'-di-O- $\beta$-glucopyranoside, a component of blue flower pigment of Salvia patens, and seven chiral analogues. Tetrahedron 60, 2025-2034

Parr, A.J., Bolwell, G.P., 2000. Phenols in the plant and in man. The potential for possible nutritional enhancement of the diet by modifying the phenols content or profile. Journal of Science, Food and Agriculture 80, 985-1012.

Patil, B.S., Jayaprakasha, G.K., Chidambara-Murthy, K.N., Vikram, A., 2009a. Bioactive compounds: historical perspectives, opportunities, and challenges. Journal of Agricultural and Food Chemistry 57, 8142-8160. 


\section{Version définitive du manuscrit publiée dans / Final version of the manuscript published in : \\ Journal of Food Composition and Analysis (2014),vol 33, p 85-104, DOI: 10.1016/j.jfca.2013.11.004 Journal homepage: www.elsevier.com/locate/jfca}

Patil, J.R., Murthy, K.N.C., Jayaprakasha, G.K., Chetti, M.B., Patil, B.S., 2009b. Bioactive compounds from Mexican lime (Citrus aurantifolia) juice induce apoptosis in human pancreatic cells. Journal of Agricultural and Food Chemistry 57, 1093310942.

Peng, H., Cheng, F., Huang, Y., Chen, C., Tsai, T., 1998. Determination of naringenin and its glucuronide conjugate in rat plasma and brain tissue by high-performance liquid chromatography. Journal of Chromatography B: Biomedical Sciences and Applications 714, 369-374.

Pepper, M.S., Hazel, S.J., Hampel, M., Schleuning, W., 2004. 8-Prenylnaringenin, a novel phytoestrogen, inhibits angiogenesis in vitro and in vivo. Journal of Cellular Physiology 199, 98-107.

Pereira, R.M.S., Andrades, N.E.D., Paulino, N., Sawaya, A.C.H.F., Eberlin, M.N., Marcucci, M.C., Favero, G.M., Novak, E.M., Bydlowski, S.P., 2007. Synthesis and characterization of a metal complex containing naringin and $\mathrm{Cu}$, and its antioxidant, antimicrobial, antiinflammatory and tumor cell cytotoxicity. Molecules 12, 1352-1366

Peschel, W., Sànchez-Rabaneda, F., Diekmann, W., Plescher, A., Gartzìa, I., Jiménez, D., Lamuela-Raventós, R., Buxaderas, S., Codina, C., 2006. An industrial approach in the search of natural antioxidants from vegetable and fruit wastes. Food Chemistry 97, 137-150.

Peterson, J., Dwyer, J., Beecher, G., Bhagwat, S.A., Gebhardt, S.E., Haytowitz, D.B., Holden, J.M., 2006a. Flavanones in oranges, tangerines (mandarins), tangors, and tangelos: a compilation and review of the data from the analytical literature. Journal of Food Composition and Analysis 19, S66-S73.

Peterson, J., Beecher, G., Bhagwat, S., Dwyer, J.T., Gebhardt, S.E., Haytowitz, D.B., Holden, J.M., 2006b. Flavanones in grapefruit, lemons, and limes: a compilation and review of the data from the analytical literature. Journal of Food Composition and Analysis 19, S74-S80.

Pietta, P.G., 2000. Flavonoids as antioxidants. Journal of Natural Products 63, 10351042.

Ramful, D., Tarnus, E., Aruoma, O.I., Bourdon, E., Bahorun, T., 2011. Polyphenol composition, vitamin C content and antioxidant capacity of Mauritian citrus fruit pulps. Food Research International 44, 2088-2099.

Rawel, H.M., Meidtner, K., Kroll, J., 2005. Binding of selected phenolic compounds to proteins. Journal of Agricultural and Food Chemistry 53, 4228-4235.

Rodriguez, J., Yáñez, J., Vicente, V., Alcaraz, M., Benavente-García, O., Castillo, J., Lorente, J., Lozano, J.A., 2002. Effects of several flavonoids on the growth of B16F10 and SK-MEL-1 melanoma cell lines: relationship between structure and activity. Melanoma Research 12, 99-107.

Roowi, S., Mullen, W., Edwards, C.A., Crozier, A., 2009. Yoghurt impacts on the excretion of phenolic acids derived from colonic breakdown of orange juice flavanones in humans. Molecular Nutrition and Food Research 53, S68-S75.

Sadeghipour, M., Terreux, R., Phipps, J., 2005. Flavonoids and tyrosine nitration: structure-activity relationship correlation with enthalpy of formation. Toxicology In Vitro 19, 155-165.

Sakata, K., Hirose, Y., Qiao, Z., Tanaka, T., Mori, H., 2003. Inhibition of inducible isoforms of cyclooxygenase and nitric oxide synthase by flavonoid hesperidin in mouse macrophage cell line. Cancer Letters 199, 139-145.

Schijlen, E.G., Ric de Vos, C., van Tunen, A.J., Bovy, A.G., 2004. Modification of flavonoid biosynthesis in crop plants. Phytochemistry 65, 2631-2648.

Schindler, R., Mentlein, R., 2006. Flavonoids and vitamin E reduce the release of the angiogenic peptide vascular endothelial growth factor from human tumor cells. Journal of Nutrition 136, 1477-1482.

Shi, L., Feng, X.E., Cui, J.R., Fang, L.H., Du, G.H., Li, Q.S., 2010. Synthesis and biological activity of flavanone derivatives. Bioorganic and Medicinal Chemistry Letters 20, 5466-5468.

Si-Ahmed, K., Tazerouti, F., Badjah-Hadj-Ahmed, A.Y., Aturki, Z., Orazio, G.D., Rocco, A., Fanali, S., 2010. Analysis of hesperetin enantiomers in human urine after ingestion of blood orange juice by using nano-liquid chromatography. Journal of Pharmaceutical and Biomedical Analysis 51, 225-229.

Silberberg, M., Gilizquierdo, A., Combaret, L., Remesy, C., Scalbert, A., Morand, C., 2006. Flavanone metabolism in healthy and tumor-bearing rats. Biomedical Pharmacotherapy 60, 529-535.

Silverstein, D.M., 2009. Inflammation in chronic kidney disease: role in the progression of renal and cardiovascular disease. Pediatric Nephrology 24, 14451452.

Simmonds, M.S.J., 2001. Importance of flavonoids in insect-plant interactions: feeding and oviposition. Phytochemistry 56, 245-252.

Slimestad, R., Fossen, T., Verheul, M.J., 2008. The flavonoids of tomatoes. Journal of Agricultural and Food Chemistry 56, 2436-2441.

So, F., Guthrie, N., Chambers, A., Moussa, M., Carroll, K., 1996. Inhibition of human breast cancer cell proliferation and delay of mammary tumorigenesis by flavonoids and citrus juices. Nutrition and Cancer 26, 167-181.

Sood, S., Arora, B., Bansal, S., Muthuraman, A., Gill, N.S., Arora, R., Bali, M., Sharma, P.D., 2009. Antioxidant, anti-inflammatory and analgesic potential of the Citrus decumana L. peel extract. Inflammopharmacology 17, 267-274.

Sood, S., Muthuraman, A., Arora, B., Bansal, S., Bali, M., Sharma, P.D., 2010. Potential effect of Citrus decumana extract on stress induced peptic ulcer in rat. Latin American Journal of Pharmacy 29, 52-56.

Sugio, S., Kashima, A., Mochizuki, S., Noda, M., Kobayashi, K., 1999. Crystal structure of human serum albumin at $2.5 \AA$ resolution. Protein Engineering 12, 439-446.

Sulkowska, A., 2002. Interaction of drugs with bovine and human serum albumin. Journal of Molecular Structure 614, 227-232.

Tomas-Barberan, F.A., Clifford, M.N., 2000. Flavanones, chalcones and dihydrochalcones - nature, occurrence and dietary burden. Journal of the Science of Food and Agriculture 80, 1073-1080.
Tripoli, E., Guardia, M.L., Giammanco, S., Majo, D.D., Giammanco, M., 2007. Citrus flavonoids: molecular structure, biological activity and nutritional properties: a review. Food Chemistry 104, 466-479.

Trzeciakiewicz, A., Habauzit, V., Mercier, S., Barron, D., Urpi-Sarda, M., Manach, C., Offord, E., Horcajada, M.N., 2010. Molecular mechanism of hesperetin-7-Oglucuronide, the main circulating metabolite of hesperidin, involved in osteoblast differentiation. Journal of Agricultural and Food Chemistry 58, 668-675.

Tsai, T.H., 2002. Determination of naringin in rat blood, brain, liver, and bile using microdialysis and its interaction with cyclosporin A, a P-glycoprotein modulator. Journal of Agricultural and Food Chemistry 50, 6669-6674.

Tsimogiannis, D., Samiotaki, M., Panayotou, G., Oreopoulou, V., 2007. Characterization of flavonoid subgroups and hydroxyl substitution by HPLC-MS/MS. Molecules 12, 593-606.

United States Department of Agriculture/Foreign Agricultural Service, 2010. Citrus: World Markets and Trade.. Available from: http://www.fas.usda.gov (accessed 28.09.2010).

Vafeiadou, K., Vauzour, D., Lee, H.Y., Rodriguez-Mateos, A., Williams, R.J., Spencer J.P.E., 2009. The citrus flavanone naringenin inhibits inflammatory signalling in glial cells and protects against neuroinflammatory injury. Archieves in Biochemistry and Biophysics 484, 100-109.

Van Acker, S.A.B.E., Groot, M.J.D., Berg, D.J.V.D., Tromp, M.N.J.L., Kelder, G.D.O.D., Vijgh, W.J.F.V.D., Bast, A., 1996. A quantum chemical explanation of the antioxidant activity of flavonoids - chemical research in toxicology. Chemical Research in Toxicology 9, 1305-1312.

Vane, J., Botting, R., 1987. Inflammation and the mechanism of action of antiinflammatory drugs. FASEB Journal 1, 89-96.

Varshney, A., Sen, P., Ahmad, E., Rehan, M., Subbarao, N., Khan, R.H., 2010. Ligand binding strategies of human serum albumin: how can the cargo be utilized? Chirality 22, 77-87.

Veitch, N.C., Grayer, R.J., 2006. Chalcones, dihydrochalcones, and aurones. In: Andersen, O.M., Markham, K.R. (Eds.), Flavonoids: Chemistry, Biochemistry and Applications. CRC Press, Taylor \& Francis Group, Boca Raton, FL, pp. 1003-1100.

Veitch, N.C., Grayer, R.J., 2008. Flavonoids and their glycosides, including anthocyanins. Natural Prodcuts Representation 25, 555.

Vinatoru, F., 2001. An overview of the ultrasonically assisted extraction of bioactive principles from herbs. Ultrasonics Sonochemistry 8, 303-313.

Wang, L., Weller, C.L., 2006. Recent advances in extraction of nutraceuticals from plants. Trends in Food Science and Technology 17, 300-312.

Wang, Y., Zhang, H., Zhang, G., Tao, W., Tang, S., 2007. Interaction of the flavonoid hesperidin with bovine serum albumin: a fluorescence quenching study. Journal of Luminescence 126, 211-218.

Wang, X., Sakurai, T., Chen, X., Sun, H., Wang, Z., Sun, Q., Sun, W., Cao, H., 2008 Hydrolysis of flavanone glycosides and degradation of the corresponding aglycones from dried immature fruit by human fecal flora. Planta Medica 74, $1751-1755$.

Wilcox, L.J., Borradaile, N.M., Dreu, L.E.D., Huff, M.W., 2001. Secretion of hepatocyte $A p o B$ is inhibited by the flavonoids, naringenin and hesperetin, via reduced activity and expression of ACAT2 and MTP. Journal of Lipid Research 42, $725-734$.

Xie, M., Xu, X., Wang, Y., 2005a. Interaction between hesperetin and human serum albumin revealed by spectroscopic methods. Biochimica et Biophysica Acta $1724,215-224$

Xie, M.X., Xu, X.Y., Wang, Y.D., Liu, Y., 2005b. Spectroscopic investigation of the interaction between 2,3-dihydro-4',5,7-trihydroxyflavone and human serum albumin. Acta Chimica Sinica 63, 2055-2062.

Xu, G., Ye, X., Chen, J., Liu, D., 2007. Effect of heat treatment on the phenolic compounds and antioxidant capacity of citrus peel extract. Journal of Agricultural and Food Chemistry 55, 330-335.

Xu, G.H., Chen, J.C., Liu, D.H., Zhang, Y.H., Jiang, P., Ye, X.Q., 2008. Minerals, phenolic compounds, and antioxidant capacity of citrus peel extract by hot water. Journal of Food Science 73, C11-C18.

Xu, L., Yang, Z.L., Li, P., Zhou, Y.Q., 2009. Modulating effect of hesperidin on experimental murine colitis induced by dextran sulfate sodium. Phytomedicine 16, 989-995.

Ye, H., Xu, H., Yu, C., Dai, Y., Liu, G., Xu, W., Yuan, S., 2009. Hydroxylation of naringin by Trichoderma harzianum to dramatically improve its antioxidative activity. Enzymology, and Microbiology Technology 45, 282-287.

Ye, X.Q., Chen, J.C., Liu, D.H., Jiang, P., Shi, J., Xue, S., Wu, D., Xu, J.G., Kakud, Y., 2011. Identification of bioactive composition and antioxidant activity in young mandarin fruits. Food Chemistry 124, 1561-1566.

Yu, J., Dandekar, D.V., Toledo, R.T., Singh, R.K., Patil, B.S., 2007. Supercritical fluid extraction of limonoids and naringin from grapefruit (Citrus paradisi Macf.) seeds. Food Chemistry 105, 1026-1031.

Zhang, Y., Li, Y., Dong, L., Li, J., He, W., Chen, X., Hu, Z., 2008. Investigation of the interaction between naringin and human serum albumin. Journal of Molecular Structure $875,1-8$.

Zia-ur-Rehman, 2006. Citrus peel extract - a natural source of antioxidant. Food Chemistry 99, 450-454.

Zill-e-Huma, Abert-Vian, M., Maingonnat, J.F., Chemat, F., 2009. Clean recovery of antioxidant flavonoids from onions: optimising solvent free microwave extraction method. Journal of Chromatography A 1216, 7700-7707.

Zsila, F., Bikádi, Z., Simonyi, M., 2003. Probing the binding of the flavonoid, quercetin to human serum albumin by circular dichroism, electronic absorption spectroscopy and molecular modelling methods. Biochemical Pharmacology 65 447-456. 